\title{
LA COMERCIALIZACIÓN DE PETRÓLEO ENTRE MÉXICO Y ESTADOS UNIDOS EN EL MARCO DEL TRATADO DE $1942^{1}$
}

\author{
Isabel Avella Alaminos \\ Universidad Nacional Autónoma de México \\ Anabel Hernández Romero \\ Centro de Investigación y Docencia Económicas
}

\section{INTRODUCCIÓN}

Elcomercio exterior representa uno de los rubros más impor-
un país son importaciones para otro son exportaciones, por lo
que el comercio es una conexión entre economías en que cada
una de las partes busca negociar a su favor modificando el marco
legal y político establecido. Así, dentro de la historia económi-
ca, el análisis del comercio de las naciones nos permite conocer

Fecha de recepción: 31 de octubre de 2016

Fecha de aceptación: 30 de mayo de 2017

\footnotetext{
${ }^{1}$ Agradecemos el apoyo de Alejandro Rodríguez Cadengo, quien como participante del XXV Verano de la Investigación capturó información de los Anuarios de Comercio Exterior; al personal del Archivo Histórico de la Secretaría de Relaciones Exteriores y del Archivo Histórico de El Colegio de México, así como a los dictaminadores, cuyas sugerencias nos permitieron mejorar la versión original del artículo.
} 
la vinculación entre política y economía, poder y mercados, intereses y decisiones. Es precisamente esta perspectiva multidimensional la que rescata el neoinstitucionalismo histórico e inspira, en parte, el presente trabajo.

El objetivo de este artículo es examinar una experiencia concreta de estas relaciones de poder, a saber, cómo se desarrolló la compra-venta de petróleo y sus derivados entre México y Estados Unidos de 1943 a 1950, y qué consecuencias tuvo para ambas economías mientras estuvo vigente el tratado comercial que ambos países firmaron a finales de 1942.

Durante la segunda guerra mundial el petróleo reafirmó su papel como un bien estratégico. Este contexto agilizó la resolución de la indemnización a las compañías estadounidenses expropiadas en 1938 y reactivó el comercio bilateral de petróleo, lo cual, en principio, resultó conveniente tanto para México como para Estados Unidos. ${ }^{2}$ Por ello, el tratado comercial de 1942 incluyó varias fracciones de bienes de la industria petrolera.

En consonancia con el papel estratégico que el petróleo tuvo en el ámbito internacional desde comienzos del siglo xx, el oro negro ha sido objeto de gran número de estudios históricos. Para el caso de México, la literatura sobre el tema es abundante. No obstante, la mayor parte de las obras se circunscriben a tres periodos: la revolución mexicana, la expropiación petrolera de 1938 y el auge exportador petrolero en la década de 1970. Sobre el primer periodo destacan, entre otros, los trabajos de Jonathan Brown, María Rubio y Stuart Baldrige; acerca de la segunda coyuntura, los textos de Lorenzo Meyer, Jesús Silva Herzog y Cecilia Zuleta; en torno a la tercera etapa cabe mencionar la obra de Olga Pellicer. ${ }^{3}$ La década de 1940 ha sido menos estudiada.

\footnotetext{
2 Torres, México en la Segunda Guerra Mundial, p. 156.

${ }^{3}$ Brown, Oil and Revolution in Mexico (1993); Rubio, "The Role of Mexico"; Meyer, México y Estados Unidos en el conflicto petrolero, Silva Herzog, Historia de la expropiación de las empresas petroleras (1973) en p. 50, y ZuLETA y KIDDLE (comps.), La expropiación petrolera mexicana en la prensa latinoa-
} 
Los textos que analizan el devenir petrolero en dicha década se refieren, por un lado, a las relaciones diplomáticas MéxicoEstados Unidos a propósito del petróleo; por otro, a la industria petrolera mexicana y estadounidense, sin profundizar en sus transacciones internacionales; $y$, finalmente, al giro de la política petrolera estadounidense en el ámbito internacional. Los únicos estudios que mencionan el tema del intercambio bilateral, pero no lo desarrollan, son los de J. Richard Powell, Thomas W. Clash y un artículo de Susana Chacón, citados en la bibliografía. Por su parte, los estudios sobre el Tratado de 1942 ofrecen aproximaciones generales que sólo mencionan la cuestión petrolera; destacan en este grupo los análisis de Blanca Torres, Susana Chacón e Isabel Avella. En suma, las investigaciones sobre los años cuarenta que se han realizado hasta ahora se enfocan en los conflictos político diplomáticos y no explican qué sucedió con el comercio bilateral de petróleo.

Por ello, el presente artículo analiza justamente el desarrollo de la compraventa de productos petroleros entre México y Estados Unidos en el marco del tratado comercial de 1942 y sus consecuencias para ambas economías. La hipótesis de la que partimos fue que el intercambio bilateral de petróleo y sus derivados creció y se diversificó a causa del tratado comercial de 1942, pero la evidencia examinada nos llevó a reformularla. Dicho comercio varió según el producto y durante la vigencia del acuerdo no se incorporaron a él tantos artículos nuevos del giro.

Vale la pena hacer dos precisiones. El objetivo de este primer análisis fue analizar el flujo comercial a partir de la comparación de las estadísticas mexicanas; puesto que los datos de comercio ofrecidos por éstas son coincidentes a nivel agregado, pero no en el registro por producto, fue necesario confrontarlas para

mericana: antología documental (2013); PeLLICER, "El petróleo en la política de Estados Unidos hacia México”, y la obra colectiva Jaime Ros, et al., El ange petrolero. 
elaborar una sola serie. Trabajamos con los Anuarios Estadísticos de Comercio Exterior publicados por la Dirección General de Estadística de la Secretaría de la Economía Nacional (19391942), la Secretaría de Economía (1943-1957) y la Secretaría de Industria y Comercio (1958-1961) de México -en adelante SEN, SE y SIYC, respectivamente-, los Anuarios Estadísticos de los Estados Unidos Mexicanos de las mismas secretarías y los informes del Banco Nacional de Comercio Exterior (Bancomext). Además, utilizamos documentación mexicana y estadounidense de la época, proveniente de los archivos mexicanos de Relaciones Exteriores y de El Colegio de México, y documentos estadounidenses disponibles en la biblioteca de El Colegio de México. La exploración del Archivo Histórico de Petróleos Mexicanos no arrojó información sobre los años cuarenta. También nos apoyamos en bibliografía secundaria. La comparación a futuro con datos estadounidenses es, sin duda, necesaria, pero presenta dificultades por la falta de uniformidad de la información (en valores, volúmenes y nomenclatura), por lo que ha quedado fuera del alcance del presente artículo y se desarrollará posteriormente. Cuando fue pertinente, consultamos datos específicos en los Minerals Yearbooks del Bureau of Mines (BM). ${ }^{4}$ Por otro lado, en virtud de que esta investigación específica forma parte de un proyecto de mayor envergadura sobre el Tratado de 1942, con el fin de comparar el desempeño de las distintas mercancías involucradas en el acuerdo, optamos por trabajar sólo con los valores comerciales a precios constantes. ${ }^{5}$

\footnotetext{
${ }^{4}$ Los Minerals Yearbooks sólo registran volúmenes comerciados enfocados en los productos estadounidenses de exportación, con la desventaja de que manejan el sistema anglosajón de medidas. Por tanto, ni siquiera los volúmenes son directamente comparables, es necesario realizar varias conversiones antes de llevar a cabo esta confrontación.

${ }^{5}$ No obstante, como se ha hecho notar en uno de los dictámenes, en el caso específico del petróleo también valdría la pena comparar estos resultados con el comportamiento de su intercambio en términos de volumen para, quizá, matizar esta aproximación inicial.
} 
El texto está dividido en cuatro apartados. Para comenzar, presentamos algunos antecedentes. A continuación, identificamos qué concesiones específicas recibieron los productos petroleros en el Tratado. En el tercero y cuarto apartados establecemos cuál fue la trayectoria del valor de las exportaciones e importaciones bilaterales de productos petroleros entre 1943 y 1950, tanto dentro como fuera del acuerdo, y cómo se relacionó con las necesidades y características de los mercados internos de México y Estados Unidos. Para evaluar el impacto del Tratado desde una perspectiva más amplia, calculamos el índice de concentración de dicho comercio entre 1934 y 1960. Al mencionar exportaciones e importaciones, nos referiremos en todo momento a las exportaciones e importaciones hechas por México. Con base en el caso del petróleo, en las conclusiones sopesamos las posibilidades y restricciones que trajo consigo el Tratado de 1942.

\section{ANTECEDENTES: EL CONTEXTO BÉLICO, EL PETRÓLEO} Y LA NEGOCIACIÓN DEL TRATADO

La industria petrolera mexicana inició a finales del siglo xIX, pero devino un elemento de conflicto con Estados Unidos a partir de que la Constitución de 1917 declaró al petróleo propiedad de la nación y sentó así las bases para acotar la actividad de las compañías extranjeras del ramo en México. Durante la primera guerra mundial el comercio petrolero entre México y Estados Unidos se incrementó, pero las tensiones bilaterales continuaron después de 1918 y se agudizaron en 1925, cuando el gobierno de Plutarco Elías Calles promulgó una Ley Petrolera y refrendó con ella el carácter de utilidad pública de esta industria. Las fricciones de México con Estados Unidos, a propósito del petróleo, disminuyeron en las postrimerías de los años veinte gracias a que el descubrimiento de nuevos yacimientos en otras partes del mundo, como Venezuela, hizo que la relevancia de México como país petrolero disminuyera; a la par, México 
incrementó su consumo de productos petroleros conforme su mercado interno se expandió. No obstante, el conflicto bilateral repuntó a raíz de la expropiación petrolera que el gobierno de Lázaro Cárdenas llevó a cabo en marzo de 1938. Las empresas estadounidenses afectadas realizaron un boicot contra las exportaciones mexicanas y el gobierno de Estados Unidos tomó una serie de represalias contra México. ${ }^{6}$ En este marco, el inicio de la segunda guerra mundial en septiembre de 1939 abrió un espacio para distender las relaciones bilaterales.

Para cuando estalló la segunda guerra mundial, el uso del petróleo como fuente de energía a nivel internacional todavía no se extendía a todos los ámbitos ni a todo el orbe por igual, pero su relevancia bélica era ya incuestionable. ${ }^{7}$ Estados Unidos, a la sazón el principal productor del ramo, continuó vendiendo petróleo y derivados incluso a los países del Eje, pese al apoyo que brindó desde un principio a los aliados. ${ }^{8}$ Por su parte, México fungió también como proveedor de las naciones del Eje y buscó fortalecer sus transacciones petroleras con otros países latinoamericanos. ${ }^{9}$

${ }^{6}$ Uhthoff López, "La industria"; Lavín, El problema petrolero y Meyer, México y los Estados Unidos.

7 Esto se había hecho evidente desde la gran guerra: “[...] la facilidad con la que un barco de guerra puede abastecerse de petróleo mediante buques-tanque que acompañan a la flota, gracias a una manguera larga y flexible, incluso en aguas picadas estando en el mar, es una gran ventaja que afectará la estrategia naval del futuro en una forma considerable"; MitzaKis, The Oil Encyclopedia, p. 354. Véanse también DeNovo, "The Movement", pp. 855, 874; Schurr, Energy, p. 2, y Ruвio, “The Role of Mexico", pp. 77-78.

${ }^{8}$ Por ejemplo, proporcionó gasolina, keroseno, petróleo combustible y aceite diésel, así como ceras, a Italia y Japón. BM, Minerals Yearbook 1941, p. 1017, y Minerals Yearbook 1940, p. 1024. Estos ejemplares y los otros Minerals Yearbook citados en el artículo fueron revisados en la página http://digicoll.library.wisc.edu/cgi-bin/EcoNatRes/EcoNatResidx? type=browse\&scope=ECONATRES.MINERALSYEARBK. Consultados en febrero de 2015.

${ }^{9}$ Con Brasil el comercio de petróleo fue la línea central de su intercambio 
Fue a partir de diciembre de 1941 cuando este panorama comercial se transformó a causa del ataque japonés a Pearl Harbor, motivado, entre otros factores, por la decisión estadounidense de no venderle más petróleo a Japón. Estados Unidos declaró entonces la guerra a los países del Eje. México hizo lo propio unos meses más tarde, en junio de 1942, a raíz del hundimiento del Potrero del Llano, un buque petrolero mexicano que en mayo de ese año navegaba cerca de la costa de Florida cuando fue atacado por un submarino alemán; el incidente fue sucedido por el hundimiento de un segundo buque mexicano. ${ }^{10}$

En este contexto, Estados Unidos y México reforzaron su control de la distribución de materiales estratégicos, el petróleo entre ellos. La coyuntura también propició la concreción de una serie de acuerdos de diversa índole: de reclamaciones, militar, financiero (plata, estabilización monetaria y créditos), laboral y comercial..$^{11} \mathrm{~A}$ lo largo de las negociaciones que culminaron con la normalización de estos últimos vínculos, el petróleo tuvo un papel central. Mientras que Estados Unidos insistía en el intercambio de productos esenciales para la guerra y en la necesidad de evitar que éstos cayeran en manos enemigas, México condicionó la concesión de facilidades comerciales en otros productos a la resolución del conflicto derivado de la expropiación petrolera. El nacionalismo petrolero mexicano seguía en pie. ${ }^{12}$

\footnotetext{
comercial; con Argentina pudo haber logrado la venta de aceite combustible, pero Pemex no tuvo barcos para entregar el producto; con Chile hubo intenciones de comercio que se basaban en el trueque: México recibiría salitre, vino, frijol y maíz a cambio de petróleo y azúcar. VeGA, Historia, cap. 9.

10 Garza Elizondo, Fundamentos y prioridades, p. 30.

${ }^{11}$ Chacón, La relación entre México y los Estados Unidos.

12 Aunque desde su creación Petróleos Mexicanos tuvo el objetivo de “[...] permitir al Estado organizar la industria petrolera y gasera, así como promover su desarrollo [...]", en los años cuarenta esta meta no se pensaba como incompatible con su vertiente exportadora. Rousseau, América Latina y petróleo, p. 250.
} 
Fue así como a finales de 1941 Estados Unidos y México iniciaron pláticas paralelas para finiquitar el tema de la expropiación y redactar un tratado comercial bilateral. ${ }^{13}$ Por lo que respecta al petróleo, entre 1941 y 1942 se sucedieron varios hechos importantes. A finales de 1941 tuvieron lugar el avalúo de los bienes petroleros expropiados a las compañías estadounidenses y la declaración de Manuel Ávila Camacho en la que dio su visto bueno a la participación del capital extranjero en la industria petrolera mexicana. En marzo de 1942 México solicitó un préstamo estadounidense para rehabilitar la industria mexicana del petróleo. En abril se estableció el monto de indemnización que México tendría que pagar a las empresas estadounidenses y en julio se pactó un acuerdo para rentar barcos petroleros mexicanos a Estados Unidos. ${ }^{14}$ Pese a que las discrepancias en torno a la presencia extranjera en la industria petrolera mexicana continuaron, la relación bilateral mejoró gracias a estos avances. ${ }^{15}$

La idea de un tratado comercial recíproco se había discutido desde tiempo atrás, pero fue recuperada en el contexto de la negociación para resolver el tema petrolero. Aunque las conversaciones para llegar a un acuerdo iniciaron en 1941, no fue sino en abril de 1942 cuando se anunció la intención formal de concretar el tratado comercial. ${ }^{16}$ Para analizar la inclusión del

13 “[...] El Secretario Duhart estuvo la mañana de hoy con los funcionarios del Departamento de Estado, para averiguar la posibilidad de que, en el momento de la firma de los convenios sobre petróleo, etcétera, el Gobierno de los Estados Unidos hiciera una declaración respecto a su intención de negociar con el Gobierno de México, un Tratado de Comercio.", AHSRE, III-122-43 VI, s. f. Documento confidencial de Francisco Castillo Nájera, 29 de septiembre de 1941, p. 1.

${ }^{14}$ AHSRE, III-122-43-VII, s. f. [Exposición sobre el Tratado en el Senado de la República], s. f., p. 4 y Memorándum confidencial del Lic. Ramón Beteta, 14 de julio de 1942, p. 1, AHSRE, III-122-43-VI, s. f. Memorándum del Consejo Superior Ejecutivo de Comercio, 24 de noviembre de 1941, 3 pp., y Clash, United States Efforts to Re-enter the Mexican Petroleum Industry, pp. 3-12.

${ }_{15}$ Torres, Hacia la utopía industrial, p. 158.

${ }^{16}$ AHSRE, III-122-43-VI, s. f. Comunicaciones de Francisco Castillo Nájera, 
petróleo y sus derivados en dicho acuerdo, el gobierno mexicano designó como asesores técnicos al ingeniero José López Portillo y Weber como encargado del grupo de examen del petróleo y sus derivados importados, y al licenciado Miguel Manterola y el ingeniero Abel de la Cueva para estudiar el petróleo y sus derivados exportados. ${ }^{17}$

Desde el principio fue clara la asimetría de intereses entre las dos naciones. México hizo patente su interés por obtener concesiones para sus exportaciones petroleras, incluso se habló de buscar un arreglo especial para asegurar su venta regular. ${ }^{18}$ Sin embargo, recomendó excluir del acuerdo los aceites y grasas lubricantes estadounidenses cuyo peso fuera mayor a 5 kilos, así como la cera mineral y la parafina de procedencia americana, "[...] por tener que reservarse la libertad de modificar los aranceles de los mismos en atención a las necesidades de la industria nacional". ${ }^{19}$ Es decir, la mira estaba puesta en las exportaciones petroleras y en amortiguar los efectos de la competencia que éstas podían suponer para los requerimientos del mercado interno, no en el crecimiento de las importaciones del giro.

Por su parte, en abril de 1942, cuando las negociaciones bilaterales formales estaban comenzando, el Departamento de Estado

22 de noviembre de 1941 y 4 de abril de 1942. Sobre las negociaciones para llegar al tratado y sus características generales véanse, respectivamente, AvELLA Alaminos, "Los grupos de intereses" y Avella Alaminos, "El impacto".

17 AHSRE, III-122-43-VI, s. f. [Listado de participantes de la tercera reunión de asesores técnicos para el estudio del Tratado comercial], 23 de abril de 1942 [p. 1]. Por parte de Estados Unidos, sabemos que hubo comunicación de México con Terry Duce, jefe de la División Exterior del Coordinador del Petróleo, organismo que definiría el contingente de petróleo que México podría vender en Estados Unidos. Véase AHSRE, III-122-43-VII, s. f. Carta de Ramón Beteta, 28 de agosto de 1942, p. 1.

${ }_{18}$ AHSRE, III-122-43-VI, s. f. Memorándum del Consejo Superior Ejecutivo de Comercio, 24 de noviembre de 1941, p. 2, y Boletín de Prensa [Consejo Superior Ejecutivo de Comercio Exterior], p. 1.

19 AHSRE, III-122-43-VI, s. f. Memorándum [15 de mayo de 1942], 8 pp. y anexos, p. 1. 
de Estados Unidos señaló que “[... el el petróleo mexicano, ahora disponible sólo en los puertos del Caribe, es prácticamente inutilizable para la guerra porque hay fuentes mejor desarrolladas que abundan en el lado caribeño, y que están más cerca tanto de los destinos del Pacífico como del Atlántico". ${ }^{20}$ Más aún, en octubre de 1942, el encargado de la División Extranjera de la Office Petroleum Coordinator, James T. Duce, señaló que “[...] había llegado el momento en el que el transporte de los productos petroleros mexicanos estaban impidiendo el uso óptimo del tonelaje de los buques petroleros, y que había surgido entonces el tema de las exportaciones petroleras mexicanas". ${ }^{21}$ Esto es, las exportaciones mexicanas de petróleo competían con las necesidades bélicas de Estados Unidos.

El interés estadounidense por las exportaciones petroleras durante las pláticas bilaterales se vinculó, en primer lugar, con la necesidad de incluirlas a cambio de lograr la aprobación del tratado comercial de 1942, y en segunda instancia, con las previsiones bélicas de dicha potencia; en relación con el segundo aspecto, se subrayaba la conveniencia de velar por la conservación del petróleo mexicano. ${ }^{22}$

En virtud de estos desacuerdos entre las partes, las condiciones para las transacciones petroleras fueron las últimas en ser definidas. ${ }^{23}$ Aun cuando las negociaciones petroleras de México con Estados Unidos continuaron en 1943, para diciembre de

${ }^{20}$ Comunicación de Max Thornburg a [Laurence] Duggan, 6 de abril de 1942, s. l., 4 pp., en "Documentos", p. 1; véase también la Comunicación de [Max Thornburg] dirigida a Duggan y [Sumner] Welles, 4 de abril de 1942, s. l., 4 pp., en "Documentos", p. 1.

${ }^{21}$ Memorándum del Deparment of State, de la conversación de James T. Duce, Director de la Foreign Division Office of Petroleum Coordinator, y William A. Fowler, 8 de octubre de 1942, 2 pp., en “Documentos", p. 1.

${ }^{22}$ Carta de Harold Ickes a Cordell Hull, 24 de agosto de 1942, 2 pp., "Documentos", pp. 1-2.

${ }^{23}$ AHSRE, III-122-43-VII, s. f. [Exposición sobre el Tratado en el Senado de la República], s. f., 9 pp., p. 1. 
1942 el tratado comercial estaba listo y fue ratificado por los congresos mexicano y estadounidense, entrando en vigor el 30 de enero de 1943. A continuación, examinaremos en qué consistieron las concesiones relativas al petróleo y sus derivados.

\section{LAS CONCESIONES ARANCELARIAS AL PETRÓLEO \\ Y SUS DERIVADOS EN EL TRATADO DE 1942}

De las 354 fracciones contenidas en el Tratado, sólo 10 se refirieron al petróleo y sus derivados, incluyéndose en dos de las tres listas que integraron el acuerdo: seis en la Lista I de concesiones mexicanas a favor de importaciones estadounidenses (con 203 artículos en total) -que comprendían tres artículos en distintas presentaciones - , y cuatro en la Lista II, correspondiente a las concesiones estadounidenses a favor de exportaciones mexicanas (con 133 artículos), relativas a cinco bienes. $\mathrm{El}$ hecho de que ninguna de estas fracciones se haya incluido en la Lista III - relativa a bienes que tendrían un tratamiento arancelario especial durante la guerra-, sugiere que los acuerdos sobre petróleo se diseñaron para aplicarse en el mediano plazo, no únicamente para encarar la emergencia bélica.

\section{Lista I}

Por lo que toca a la Lista I, se incluyeron seis fracciones arancelarias del ramo energético (véase el cuadro 1): gas natural o artificial para iluminación o combustible, grasas lubricantes de distinto peso, y cera mineral y parafina. Los dos primeros artículos eran bienes de inversión, en tanto la cera pertenecía al rubro de materias industriales. Es decir, se respetó la solicitud mexicana de excluir los aceites lubricantes, no así su deseo de eliminar las grasas lubricantes de más de 5 kilos. Es dable aventurar que dicha negativa estuvo directamente relacionada con el hecho de que, al firmar el acuerdo, Estados Unidos era prácticamente 
el único abastecedor de grasas, cera y parafina para el mercado mexicano, de manera que México tenía poco margen de maniobra para negociar. ${ }^{24}$

Así, el Tratado simplemente ratificó una serie de concesiones anteriores a 1943. A cambio, México obtuvo un trato arancelario más favorable para la exportación de productos petroleros de la Lista II del acuerdo.

\section{Lista II}

Antes del Tratado, las exportaciones mexicanas de petróleo con destino a Estados Unidos estaban divididas en cuatro clasificaciones arancelarias: 1) exportaciones de México libres para el abastecimiento de barcos; 2) exportaciones libres para la refinación y la exportación; 3) exportaciones sujetas a cuota y a un impuesto especial (excise tax) de $1 / 4$ de centavo el galón, y 4) exportaciones que rebasaban la cuota y estaban sujetas a un impuesto especial de $1 / 2$ de centavo el galón. ${ }^{25}$ Con respecto a la cuota mencionada en el tercer rubro, cabe mencionar que fue establecida en el Tratado que firmaron Estados Unidos y Venezuela en diciembre de 1939. Desde el 16 de diciembre de 1939, Estados Unidos había extendido la concesión de arancel reducido de $1 / 4$-otorgado inicialmente sólo a Venezuela-a varios países latinoamericanos, México entre ellos; sin embargo, se daba el descuento únicamente a las importaciones que no rebasaran la cuota de $5 \%$ del total de la cantidad de petróleo crudo procesada en refinerías del territorio continental de Estados Unidos.

\footnotetext{
${ }^{24}$ De acuerdo con la Tariff Commission (en adelante TC) Estados Unidos monopolizaba dichas ventas, visión coincidente con los datos de los Anuarios Estadisticos de Comercio Exterior de la SEN que indican que entre 1939 y 1943 México compró $98.73 \%$ de las grasas lubricantes importadas a Estados Unidos y $99.68 \%$ de las ceras y parafinas. Véase TC, Trade Agreement, p. xii y SEN, Anuario Estadístico del Comercio 1939, 1940, 1941 y 1942.

${ }_{25}$ TC, Trade Agreement, p. xvii.
} 


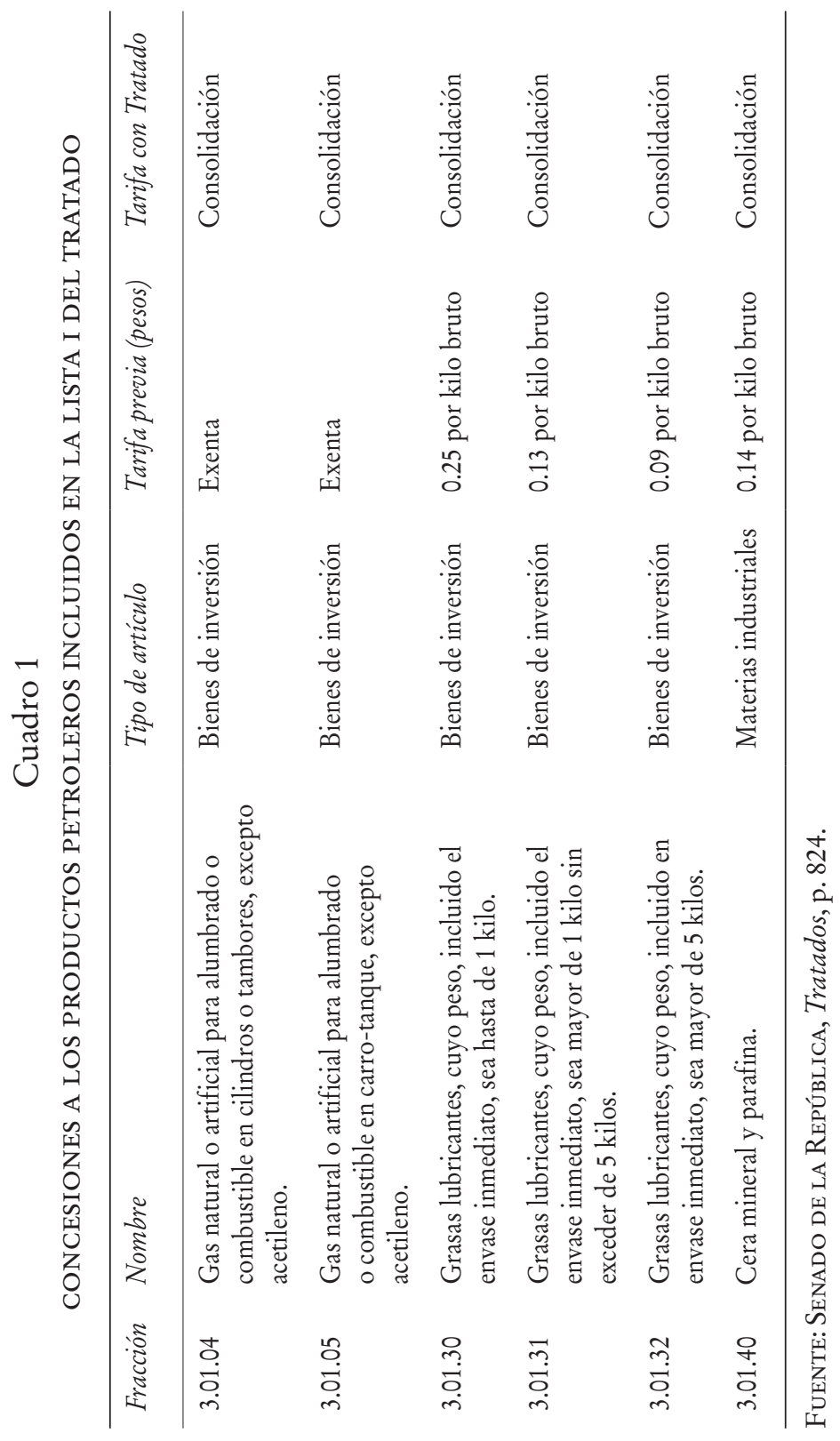




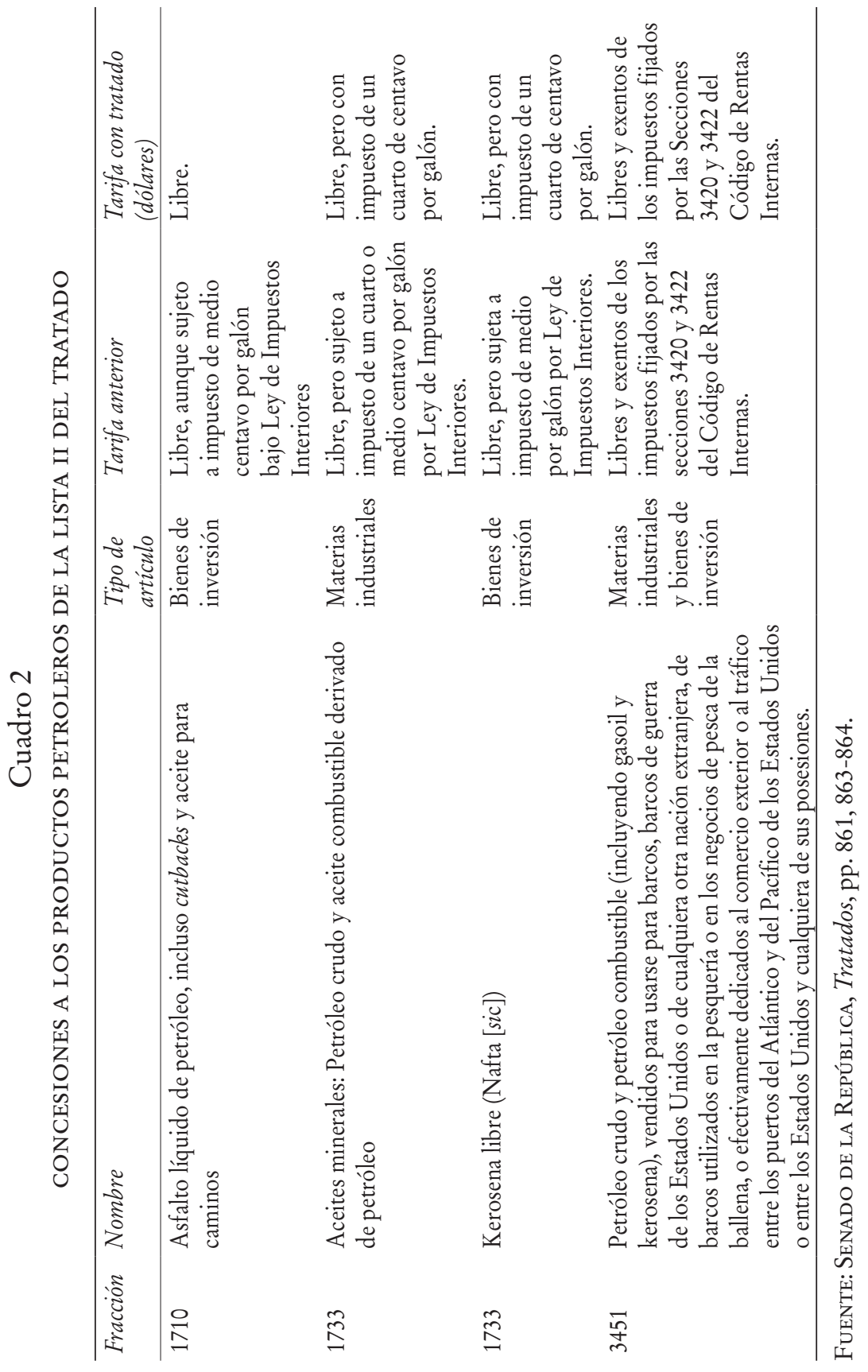


En primer lugar, la delegación mexicana se propuso obtener de Estados Unidos un aumento del contingente para el petróleo de México; Estados Unidos ofreció, en cambio, derogar el decreto presidencial que estipulaba la repartición del contingente petrolero entre los diversos países proveedores del mismo. ${ }^{26}$ Detrás de la contrapropuesta estadounidense estaba la presión de los petroleros americanos, en particular de Texas y Oklahoma, cuya producción había sido restringida durante la guerra y, por ende, se mostraban reticentes a reducir las barreras aduanales a favor del petróleo extranjero. ${ }^{27}$

A final de cuentas, en la Lista II del acuerdo se incluyeron los siguientes productos petroleros: petróleo crudo -incluyendo el topped crude petroleum-, ${ }^{28}$ petróleo o aceite combustible ${ }^{29}$ y kerosena, ${ }^{30}$ todos contemplados en el mismo párrafo arancelario de la legislación estadounidense (fracción 1733), así como el asfalto, reclasificado como asfalto de petróleo líquido, incluyendo cutbacks y bitumen o petróleo para caminos (road oil) (fracción 1710).

Aunque sus aranceles sólo fueron consolidados, se eliminó la cuota para los productos petroleros y se les otorgaron

\footnotetext{
26 AHSRE, III-122-43-VI, s. f. Nota confidencial de Ramón Beteta, 28 de agosto de 1942, p. 1.

${ }^{27}$ AHSRE, III-122-43-VI, s.f. Memorándum confidencial de Ramón Beteta, 26 de agosto de 1942, p. 1.

${ }^{28} \mathrm{El}$ petróleo crudo sin las fracciones de gasolina y keroseno, TC, Trade Agreement, p. 245.

${ }^{29}$ Según la versión del Tratado en inglés, éste también incluía la exportación de gas oil. Aunque dicho producto aparece en la fracción 3451 - relativa a productos petroleros para barcos - de la Lista II de la versión en español, Bancomext, que es la única fuente que brinda datos estadísticos de lo que se exportó e importó en el marco del Tratado, no menciona el gas oil, por lo que en el texto lo consideramos como un artículo fuera del acuerdo. Dadas las discrepancias en la nomenclatura, que se comentarán más adelante, probablemente el gas oil se registró en la denominación genérica de petróleo combustible. ${ }^{30}$ Usamos la denominación kerosena, en lugar de keroseno, como se utiliza hoy en día, porque es la que se empleaba en la época que analizamos.
} 
concesiones fiscales por lo que toca a los gravámenes internos que pagaban al entrar a Estados Unidos. En tanto que el asfalto y la kerosena quedaron exentos de impuestos, el pago de gravamen interior para el petróleo crudo y el petróleo combustible se redujo a la mitad (véase el cuadro 2). De esta manera, con el acuerdo se consolidó el tratamiento arancelario que ya recibían las exportaciones mexicanas destinadas al abastecimiento de barcos, refinación y ulterior exportación, y el impuesto para gravar todas las exportaciones petroleras mexicanas se fijó en un nivel más bajo (un cuarto de centavo de dólar por galón, en lugar de medio).

Algunos datos nos ayudan a dimensionar la magnitud de estas concesiones. En 1940 el gravamen sobre el asfalto mexicano representó $25 \%$ del valor de este bien, aun cuando se le aplicó el impuesto especial doméstico de un cuarto de centavo de dólar por galón. ${ }^{31}$ Asimismo, en 1940 la kerosena mexicana fue gravada con $13 \%$ de su valor unitario. En el caso del petróleo crudo y el petróleo combustible residual (residual fuel oil), el impuesto que pagaban antes del acuerdo equivalía, para el fragmento con gravamen preferencial, a $13-17 \%$ ad valorem, mientras que la parte fuera del trato preferente pagaba entre 23 y $33 \%$ ad valorem. Por tanto, la reducción obtenida por parte de México parecía abrir la puerta al incremento de sus exportaciones petroleras.

En síntesis, México logró negociar con Estados Unidos la inclusión en el Tratado de varios artículos de la industria petrolera. En consonancia con la preocupación externada por el gobierno de México, aun cuando seis de las diez fracciones de artículos petroleros del acuerdo fueron de importación, las mayores concesiones se dieron a las exportaciones mexicanas, registradas en la Lista II del convenio. Años después algunos industriales mexicanos señalarían que dicha apertura arancelaria únicamente permitió “[...] la eliminación de una situación

${ }^{31}$ TC, Trade Agreement, pp. 239-242. 
injustificada y de la colocación de México en condiciones de igualdad con respecto a otros países productores; y ello ni formal ni materialmente puede ser valorizado como una concesión o ventaja". ${ }^{32}$ Sin embargo, en 1942, al terminar las negociaciones, el gobierno mexicano se mostraba optimista con respecto al tratamiento que recibiría el petróleo nacional en Estados Unidos. ${ }^{33}$

En los siguientes dos apartados analizaremos las repercusiones de esta serie de concesiones para dilucidar qué tanto contribuyeron a incrementar el flujo comercial bilateral en el rubro petrolera.

Antes de entrar en materia, es pertinente aclarar que la estimación del nivel del comercio petrolero bilateral en los años cuarenta y el examen de la medida en la que el Tratado lo fomentó o no, reviste dificultades importantes. Éstas se derivan de las diferencias que hay en la terminología de la época para referirse a los bienes petroleros. Las discrepancias aparecen, incluso, dentro de las diversas fuentes mexicanas, pero se amplían al comparar las cifras mexicanas con las publicaciones estadounidenses. Lo anterior se relaciona con la ausencia de una clasificación arancelaria con vocabularios análogos en México y Estados Unidos, situación denunciada por los industriales mexicanos de la época. ${ }^{34}$ Para reconstruir los valores intercambiados en el marco del Tratado utilizamos los registros que publicó Bancomext, pues son los únicos que especifican el valor y el volumen del comercio bilateral de las mercancías incluidas en el acuerdo. Sin embargo, para reconstruir el flujo petrolero bilateral global nos apegamos a las estadísticas del Anuario Estadístico de Comercio Exterior de las SEN y SE, que confrontamos con las cifras de los informes

32 Fouque, El Tratado, p. 21.

${ }_{33}$ AHSRE, III-122-43-VII, s. f. [Exposición sobre el Tratado en el Senado de la República], s. f., p. 6.

${ }^{34}$ Fouque, El Tratado, p. 16. 
de Bancomext y los Anuarios estadísticos de los Estados Unidos Mexicanos de las dos secretarías. ${ }^{35}$

\section{LAS EXPORTACIONES PETROLERAS MEXICANAS \\ PARA ESTADOS UNIDOS (1943-1950)}

Productos exportados y nivel de exportación

De acuerdo con la SEN/sE, entre 1943 y 1950 México exportó a Estados Unidos petróleo crudo, petróleo combustible y aceite diesel, gasolina, gas oil y kerosena cruda; también se registraron exportaciones de asfalto y bitumen a Estados Unidos en 1943 y luego de 1946 a 1950, pero en cantidades mínimas.

\section{Gráfica 1}

EXPORTACIÓN DE PETRÓLEO CRUDO MEXICANO A E. U. (1943-1950) (MILES DE DÓLARES CONSTANTES 1940=100)

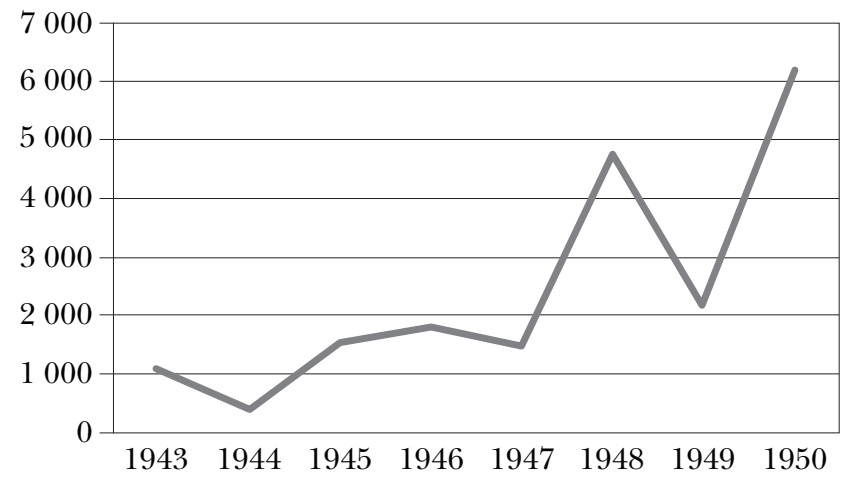

FuENTE: elaboración propia con base en BANCOMEXT, El comercio exterior, cuadro 261; Bancomext, Comercio, apéndice 17.

${ }^{35}$ Las cifras fueron convertidas a dólares constantes tomando el tipo de cambio nominal y los índices generales de precios de importaciones y exportaciones que aparecen en CÁRDENAS, La hacienda pública, cuadros A20 y A32. 
De estos artículos, aquellos que se exportaron dentro del marco del Tratado de 1942 fueron: petróleo crudo, kerosena, aceite para combustión interna (equivalente al petróleo combustible y el aceite diesel de las SEN/SE), emulsiones y soluciones de asfalto y asfaltos naturales. Por lo tanto, los bienes cuyo intercambio se realizó fuera del acuerdo fueron el gas oil, la gasolina, los aceites y grasas lubricantes y un monto mínimo de parafina en 1944. El valor de este segundo grupo de productos fue menor al del primero; representó entre 3.7 y $19.3 \%$ de las exportaciones petroleras hechas por México a Estados Unidos.

\section{Gráfica 2}

EXPORTACIONES MEXICANAS DE KEROSENA Y ACEITE PARA MOTORES A E. U. (1943-1950) (MILES DE DÓLARES CONSTANTES CON ÍNDICE POR PRODUCTO 1940=100)

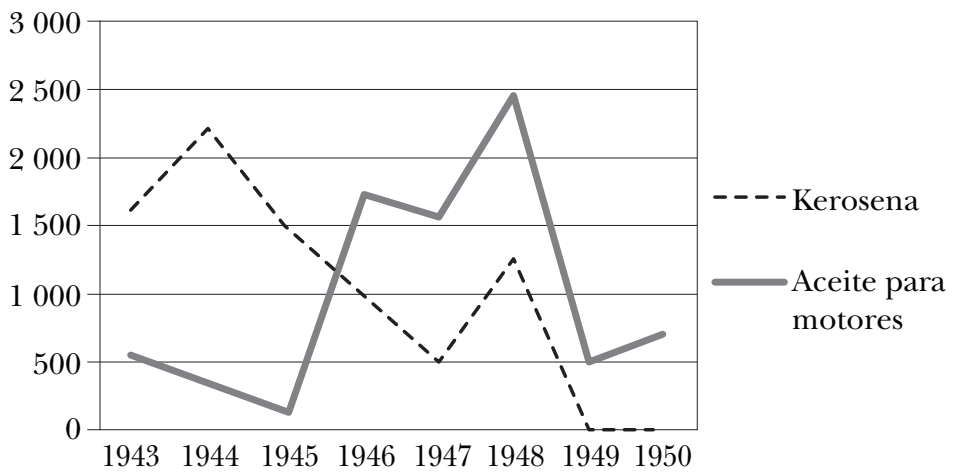

FUENTE: elaboración propia con base en las mismas fuentes de la gráfica 1.

Entre 1943 y 1950 sólo el petróleo crudo se ubicó entre los artículos con mayor valor de intercambio (es decir, superior a los 100000000 de pesos corrientes).

En segundo lugar, con niveles globales semejantes entre sí, estuvieron la kerosena y el aceite. Las transacciones de los dos productos de asfalto fueron insignificantes. El contraste, el valor 
de intercambio del petróleo crudo experimentó un ascenso a lo largo del periodo, sobre todo a partir de 1947 (gráfica 1); este dato indica que, contrario a lo esperado, el mayor nivel de transacciones se alcanzó después de 1945, no durante la guerra. Una trayectoria similar se observa en el comercio de aceite para motores (gráfica 2), cuya alza se dio de 1945 a 1948 y terminó en una abrupta caída en 1949. En contrapartida, el intercambio de kerosena sí atravesó un primer momento de auge al calor del conflicto europeo. En los tres productos, salta a la vista el efecto pasajero de las devaluaciones del peso de 1948 y 1949 en las exportaciones mexicanas, pues las gráficas muestran el alza de su venta a Estados Unidos.

Para valorar el alcance del Tratado es pertinente preguntarse si éste repercutió de alguna manera en la concentración que tuvo el comercio de México con respecto a Estados Unidos (véase la gráfica 3). Con este fin hemos recurrido al índice de concentración comercial diseñado por Hirschman en 1945. ${ }^{36}$ Además de calcular la concentración entre 1943 y 1950, extendimos la comparación hacia atrás hasta 1934, que es el primer año para el que hay registros de exportaciones e importaciones por país en las estadísticas disponibles, y hacia delante hasta 1960 para revisar la década posterior a la denuncia del acuerdo. Entre 1934 y 1960 México exportó 10 productos, de los cuales sólo uno se comercializó a partir de los años cincuenta; estos 10 productos comprenden hasta un total de 23 fracciones arancelarias, según la forma en la que se les registró en el periodo.

\footnotetext{
${ }^{36}$ Hirschman, National Power, pp. 85-160. Respecto al índice, véase también KunTz Ficker, El comercio exterior, pp. 68-69. En este texto nos apegamos a la fórmula original presentada por Hirschman: $C=\sqrt{\Sigma^{\mathrm{n}}}(\mathrm{ak} / \mathrm{A} * 100)^{2}$, donde ak es el valor comerciado de un producto por parte de un país hacia o desde otro país dado y A el total comerciado de ese mismo producto por parte del primer país en cuestión.
} 
Gráfica 3

ÍNDICE DE CONCENTRACIÓN DE LAS EXPORTACIONES PETROLERAS

DE MÉXICO, 1932-1960

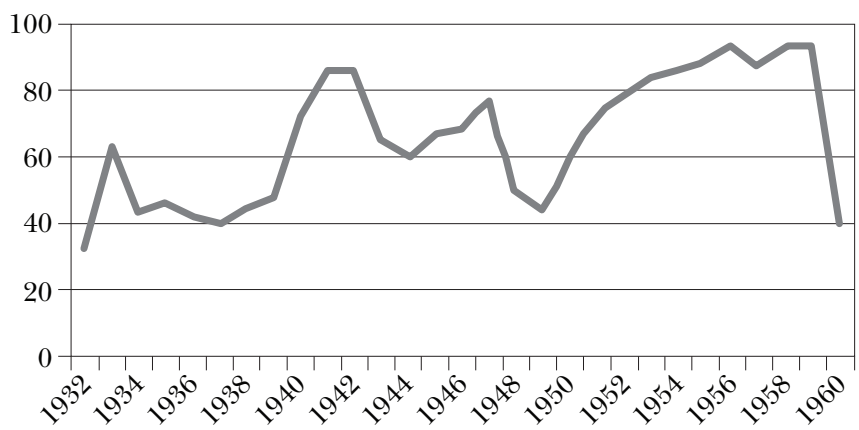

FuENTE: elaboración propia a partir de datos del cuadro A.1 del Anexo.

La gráfica nos muestra que el índice de concentración comercial de los productos petroleros durante la década de 1940 fue mayor en comparación con el de los años treinta. El país que acaparó mayor porción de las exportaciones mexicanas fue Estados Unidos (véase Anexo). En relación con los años cincuenta, sin embargo, dicha concentración fue menor y menos consistente. Dados estos datos, parecería que el Tratado sí contribuyó a incrementar el índice de concentración comercial de las exportaciones de México hacia Estados Unidos. No obstante, una mirada más detallada a la gráfica revela que la primera elevación del índice de concentración tuvo lugar antes de que se firmara el Tratado y coincide con el inicio de la segunda guerra mundial. De hecho, en el arranque del acuerdo, entre 1942 y 1944, dicho índice disminuyó para luego comenzar a recuperarse hasta 1947, pero sin alcanzar los niveles que tuvo en 1941. Este comportamiento podría vincularse con las limitaciones de abastecimiento y transporte que existieron durante la guerra.

Ahora bien, la caída en el índice de concentración entre 1947 y 1949 sugiere que la posguerra favoreció la diversificación geográfica de las exportaciones mexicanas de petróleo. A ello 
sin duda contribuyeron las ya mencionadas devaluaciones del peso mexicano de finales de los años cuarenta, que abarataron el precio de dichos bienes. Después de 1949 y durante casi toda la década de 1950 el nuevo incremento en el índice de concentración podría haber obedecido al incremento en las necesidades energéticas de Estados Unidos y su mayor dependencia de las importaciones petroleras.

Un análisis del índice de concentración por artículo petrolero de exportación arroja un panorama un poco distinto (véanse Anexo y cuadro 3). En el caso de los bienes que sí se contemplaron en el Tratado, el índice de concentración del petróleo crudo muestra que la guerra favoreció la concentración de sus ventas en Estados Unidos a un nivel superior al promedio de los años treinta y, en el primer lustro de la década de 1940, por encima del promedio de la década de los cincuenta. La concentración de la kerosena presentó una evolución similar, se mantuvo con algunos vaivenes entre 1939 y 1947 y luego descendió. En el asfalto, cuyos valores de exportación fueron muy bajos, el índice de concentración se elevó desde 1938, cayó entre 1943 y 1945 , y después se recuperó. El índice de concentración de petróleo combustible se elevó en los primeros cinco años de la década de los cuarenta y luego decreció, aunque menos que en los años treinta; en este caso las principales ventas de la década de 1940 se destinaron a Cuba.

En resumen, parece que la concentración de las exportaciones petroleras mexicanas que entraron en el Tratado a favor de Estados Unidos sí se incrementó en general en relación con la de los años treinta, aunque en la década de 1950 esta concentración tendió a ser mayor en varios productos. Sin embargo, el punto de inflexión no fue 1943 sino 1938-1939, de manera que coincidió con el inicio de la guerra, no con el del acuerdo. Dicha concentración decreció en la segunda mitad de los años cuarenta, lo cual refuerza la idea de que la guerra fue el factor que detonó esa concentración. 


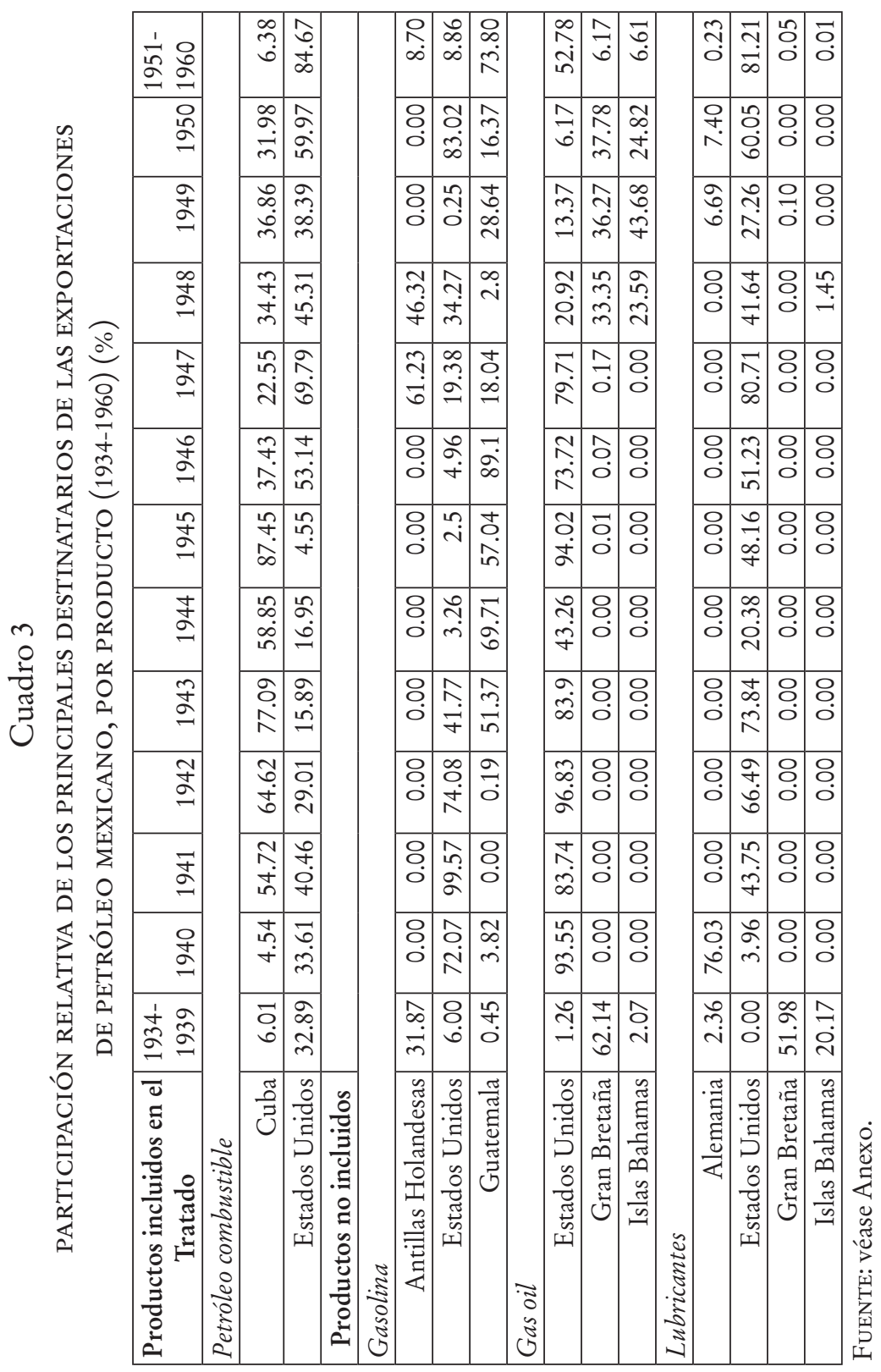


En relación con los productos de exportación que no estuvieron en el Tratado, en la gasolina el índice de concentración se elevó en los años cuarenta respecto a la década anterior, y aunque en 1940 favoreció a Estados Unidos, entre 1941 y 1946 benefició a Guatemala y en 1948 a las Antillas Holandesas. No tenemos suficientes elementos para explicar el caso de Guatemala, pero sabemos que desde los años veinte las Antillas Holandesas funcionaron como un punto de reexportación hacia Estados Unidos, ${ }^{37}$ por lo que cuando menos parte de las exportaciones que recibió pudieron haber terminado en este último. El gas oil siguió una trayectoria similar, sólo que entre 1948 y 1949, al disminuir la concentración a favor del mercado estadounidense, los principales compradores beneficiados fueron Gran Bretaña y Bahamas. ${ }^{38}$ Por lo que respecta a los lubricantes, a diferencia de lo que ocurrió con los demás bienes señalados, su concentración disminuyó en la primera parte de la guerra y creció en los años cincuenta. Además, en este producto la concentración en la década de 1930 recayó en Gran Bretaña y Bahamas, en 1940 en Alemania - cuando aún tenía comercio de compensación con México -,${ }^{39}$ y en seis años de la década de 1940 fue favorable a Estados Unidos, aunque la concentración de las compras en éste fue mayor en los años cincuenta. Destaca el hecho de que en este grupo de bienes la concentración se haya desviado de Estados Unidos. Esto, con la salvedad del petróleo combustible, no sucedió con los artículos que sí se incluyeron en el Tratado, lo cual sugiere, una vez más, que el acuerdo sí coadyuvó a reforzar el comercio bilateral de ciertos productos.

\footnotetext{
37 Rubio, Yáñez, Folchi, Carrera, “Energy”, p. 780, y Schurr, Energy, p. 112.

38 Esta diversificación se dio después de que El Águila y sus subsidiarias llegaron a un acuerdo con México para finiquitar el tema de la expropiación petrolera. Torres, México y el mundo, p. 88.

39 Avella Alaminos, “El comercio”, pp. 85-86.
} 
Ahora bien, entre 1943 y 1950 la trayectoria de la exportación de los productos de la industria petrolera mexicana, tanto dentro como fuera del acuerdo, se definió en función de cuatro factores centrales que ayudan a entender el comportamiento de los índices de concentración arriba analizados: la guerra, las necesidades y limitaciones internas de la economía mexicana, los vaivenes del mercado de la posguerra temprana, así como los requerimientos de la economía estadounidense.

Respecto al efecto de la guerra, por citar un ejemplo, en julio de 1943 el Departamento de Comercio de Estados Unidos daba cuenta de que las exportaciones mexicanas de petróleo habían descendido tanto por la interrupción de la comunicación con varios mercados extranjeros como por la reducción de la capacidad de los tanques debido a la acción de los submarinos alemanes. ${ }^{40} \mathrm{Y}$ aunque el 27 de noviembre de 1945 el gobierno mexicano levantó la mayor parte de las restricciones bélicas que pesaban sobre sus exportaciones, en el grupo de minerales no se incluyó a los combustibles. ${ }^{41}$

Independientemente del conflicto europeo, es evidente que, sobre todo en un inicio, la industria petrolera mexicana no pudo exportar tantos productos debido a las limitaciones de sus instalaciones y a la falta de nuevas explotaciones. Desde que el acuerdo se estaba negociando, cuando Estados Unidos se negó a aumentar el contingente de petróleo mexicano, Ramón Beteta - el líder de la delegación mexicana - apuntó que, incluso si éste se obtenía, en realidad no definiría el nivel de exportación hacia Estados Unidos:

Si, por el contrario, no se llega a un acuerdo respecto a la manera más conveniente de transportar el petróleo mexicano y continuamos

${ }^{40}$ Industrial Projects Unite-Bureau of Foreign and Domestic Commerce, "Mexican Pretroleum Industry", Commerce Reports (3 jul. 1943), p. 9.

${ }_{41}$ "Mexico. Tariffs and Trade Controls", Commerce Reports (12 ene. 1946), p. 23. 
atenidos a la incapacidad de los barcos que ahora tenemos; si, además, seguimos incapacitados para producir gasolina de alto octano y nuestro aceite Diesel no llena las especificaciones que exigen los submarinos ni el Bunker C las que pide [sic] la Marina norteamericana, entonces, de hecho, la cantidad que México podría enviar a este país sería muy pequeña aunque hubiésemos conseguido un contingente de veinte millones de barriles anuales. ${ }^{42}$

Así, en marzo de 1943 la producción de Pemex en el sureste de México fue inferior a la registrada en la misma época del año en 1941 y $1942 .{ }^{43}$ Con todo, esta situación fue pasajera, ya que para 1944, aunque la exportación de petróleo mexicano había disminuido, se registró un crecimiento en su producción. ${ }^{44}$ Por tanto, hubo otros factores que explican el comportamiento de las exportaciones petroleras de México.

A lo largo de todo el periodo la demanda de bienes petroleros mexicanos por parte de Estados Unidos compitió con las necesidades del mercado nacional de México en el marco de la política de sustitución de importaciones y su vinculación con un proyecto industrializador de gran envergadura, uno de cuyos pilares fue la oferta de petróleo barato. ${ }^{45}$ En este ámbito, es importante tener en cuenta tanto a los productos petroleros que se incluyeron en el Tratado, como a aquellos cuyo intercambio fue relevante, aunque haya tenido lugar al margen del acuerdo. Esto, no sólo por la importancia de su compraventa, sino porque, por ejemplo, la exportación de petróleo crudo significaba menor materia prima disponible para la producción de gasolina para el mercado local. Los datos disponibles sobre el consumo en la República hasta 1950 no dejan lugar a dudas: la demanda de productos derivados del petróleo creció en forma sostenida, en particular en lo tocante

${ }^{42}$ AHSRE, III-122-43-VI, s. f. Nota confidencial de Ramón Beteta, 28 de agosto de 1942, p. 3.

43 "Mexico. Economic Conditions", Commerce Reports (12 jun. 1943), p. 22.

${ }^{44}$ Clark, "Mexico in 1944", Commerce Reports (28 jul. 1945), p. 58.

${ }^{45}$ Fujigaki Cruz, "Periplo", pp. 406-413. 
a gasolina y, en segundo término, kerosena (véase el cuadro 4). Este panorama es refrendado por otros datos. Por ejemplo, al iniciar 1943 la venta de gasolina a Estados Unidos en los estados fronterizos se restringió, al decretarse en México su racionalización. ${ }^{46}$ De hecho, a finales de 1948 el Departamento de Comercio de Estados Unidos informó que el incremento de la demanda mexicana de productos petroleros estaba ejerciendo presión, signo de que sería necesario recortar las ventas al exterior. ${ }^{47}$

\section{Cuadro 4}

CONSUMO BRUTO TOTAL EN LA REPÚBLICA MEXICANA 1939-1950

\begin{tabular}{ccccc}
\hline Año & $\begin{array}{c}\text { Combustible } \\
\text { (miles de } \\
\text { T.M.) }\end{array}$ & $\begin{array}{c}\text { Diesel oil } \\
\text { (gasóleo) (miles } \\
\text { de T.M.) }\end{array}$ & $\begin{array}{c}\text { Nafta } \\
\text { (gasolinas) } \\
\text { (miles de L.) }\end{array}$ & $\begin{array}{c}\text { Kerosena (miles } \\
\text { de L.) (no incluye } \\
\text { tractomex) }\end{array}$ \\
\hline 1939 & 2408 & 125 & 594800 & 46599 \\
1940 & 2479 & 122 & 659552 & 55660 \\
1941 & 2572 & 151 & 768397 & 61171 \\
1942 & 2788 & 156 & 858587 & 73639 \\
1943 & 3317 & 171 & 927379 & 97884 \\
1944 & 3410 & 176 & 928545 & 138735 \\
1945 & 3599 & 188 & 1069715 & 242899 \\
1946 & 3964 & 236 & 1312280 & 284815 \\
1947 & 3391 & 734 & 1505631 & 832691 \\
1948 & 4110 & 525 & 1731352 & 717633 \\
1949 & 3882 & 751 & 1880102 & 1000318 \\
1950 & 4770 & 744 & 2135696 & 993729 \\
\hline
\end{tabular}

FuENTE: AHSRE, III/628 (72:00) 1, 1946-1948, foja 9. "Petróleo de México y su Expropiación por el Gobierno Mexicano. Informes y datos procedentes del extranjero sobre dicha expropiación." Los datos de gasolinas de 1947 a 1950 son de SE, Anuario Estadístico 1946-1950, p. 533. Los datos de kerosena, petróleo combustible y gas oil son estimaciones propias hechas a partir de las cifras de producción del mismo anuario y las de exportación de SE, Anuario Estadístico del Comercio 1947, 1948 y 1949-19 50.

46 "Mexico. Economic Conditions", Commerce Reports (6 mar. 1943), p. 19. 47 "Mexico. Airgram from U. S. Embassy Mexico City (Dated September 22, 1948)", Commerce Reports (16 oct. 1948), p. 19. 
En relación con la influencia del contexto internacional de la posguerra en el devenir de las exportaciones mexicanas, es preciso considerar que el descenso de los precios internacionales de ciertos productos petroleros en las postrimerías de la década de 1940 pudo haber desincentivado el aumento de algunas en el mediano plazo, aun cuando dicha tendencia no se reflejaba todavía en el valor ni el volumen de las ventas realizadas en 1950. Por ejemplo, en junio de 1949 se reportaba que el precio del gas oil -que México estaba en posibilidad de ofrecer en cantidades importantes - se había reducido a menos de la mitad con respecto al año anterior y sabemos que el valor de su exportación disminuyó al iniciar los años cincuenta. ${ }^{48}$

El cuarto factor determinante en la trayectoria de las exportaciones petroleras mexicanas fue la relevancia que éstas tuvieron para su destinatario. Como advertimos páginas atrás, el incentivo de Estados Unidos para comprar petróleo mexicano en los años cuarenta no fue tan apremiante. De hecho, el petróleo mexicano, en contraste con el estadounidense, era de mayor densidad y, por ello, menos adecuado para la elaboración de derivados ligeros como la gasolina. Aun así, en el marco de la guerra la perspectiva de aprovechar los recursos mexicanos para la producción de gasolina para aviones y hule sintético resultaba, sin duda, atractiva: “[...] hoy está la necesidad de generar provisiones en México para la gasolina de los aviones y otros productos petroleros sin los cuales las operaciones militares simplemente no podrían llevarse a cabo". ${ }^{49}$ La misma preocupación externaba F. D. Roosevelt en un documento dirigido al

\footnotetext{
48 “Airgram from U. S. Embassy Mexico City (Dated May 31)”, Commerce Reports (20 jun. 1949), p. 25, y Clark, "Mexico faces 1950 with Record of Recent Economic Improvement", Commerce Reports (23 ene. 1950), p. 5, y SE/SIYC, Anuario Estadístico del Comercio 1951, 1952, 1953, 1954, 1955, 1956, 1957, 1958, 1959, 1960.

${ }^{49}$ Carta de Harold Ickes a Cordell Hull, 24 de agosto de 1942, 2 pp., "Documentos", p. 1; véase también la p. 2.
} 
secretario de Estado en julio de 1944: "Lo que me preocupa es la otra cuestión - petróleo para el uso, en última instancia, de las fuerzas armadas estadounidenses-, la de las reservas [...]". ${ }^{50}$ Con esa lógica fue que el Export Import Bank de Estados Unidos extendió a Pemex un crédito de 10 millones de dólares para instalar una refinería de alto octanaje. ${ }^{51}$ Además, es pertinente advertir que a partir de 1947 Estados Unidos, que antaño había sido el mayor exportador de petróleo, devino el principal importador neto de este producto. ${ }^{52}$

Más allá de estas consideraciones, el uso de los productos derivados del petróleo en el mercado interno de Estados Unidos es otro elemento importante para explicar la demanda estadounidense de petróleo mexicano. Desde el estallido de la guerra el petróleo crudo mexicano importado - no obstante su mayor densidad - se utilizó para satisfacer las necesidades del mercado interno estadounidense. ${ }^{53}$ Por otro lado, el consumo del aceite para combustión interna siguió una trayectoria al alza, pero estacional. El uso de este producto se incrementó en transporte ferroviario y marítimo, plantas de electricidad y gas, fundidoras, minas y manufacturas, entre otros. La gasolina, derivado que, como se ha referido ya, quedó fuera del Tratado, también tuvo una demanda ascendente durante este periodo. La de la kerosena, en cambio, fue en declive, pues cubría necesidades utilitarias, es decir, se usaba como combustible para la calefacción, la cocina y la iluminación rural; sólo en ocasiones se empleaba como insumo para producir gasolina. ${ }^{54}$

Por tanto, los artículos exportados por México tuvieron valores estratégicos distintos. En función de los datos de las gráficas

\footnotetext{
${ }^{50}$ Memorándum del presidente Franklin D. Roosevelt para el secretario de Estado, Washington, 19 de julio de 1944, 2 pp., en “Documentos”, p. 1.

${ }^{51}$ Department of State, Office of the Petroleum Adviser, "Relation of a possible loan", 3 pp., en "Documentos", p. 3.

${ }^{52}$ SCHurr, Energy, pp. 43, 90.

${ }_{53}$ TC, Trade Agreement, p. xlviii.

${ }^{54}$ Hamilton, Competition in Oil, pp. 30-31, 33.
} 
del apartado anterior, se colige que la demanda estadounidense de kerosena se elevó durante la guerra, presuntamente no tanto para ser usada como combustible, sino para producir gasolina. Cuando otros insumos estuvieron disponibles, la kerosena dejó de ser tan relevante en el mercado estadounidense, a la vez que ganó mayor importancia en el mexicano. En contraste, la demanda de aceite para combustión interna siguió creciendo durante la posguerra hasta 1948 y repuntó en la década de los cincuenta. Por lo que toca al petróleo crudo, si bien la exportación mexicana fue creciente, cabe subrayar que su participación relativa menguó en forma considerable pues, de acaparar $27 \%$ de la demanda estadounidense en 1942, para 1949 constituía sólo $4 \%$ de las importaciones estadounidenses de dicho producto. ${ }^{55}$ En este sentido, no hay que perder de vista que al terminar la guerra la ventaja que obtuvo México gracias a su colindancia con Estados Unidos se diluyó y enfrentó, de nueva cuenta, la competencia de Venezuela y la creciente importancia de Medio Oriente en el mercado petrolero internacional..$^{56}$

En resumen, es importante subrayar que, a contrapelo de la expectativa inicial de México, en realidad el Tratado no dio lugar al incremento constante de las exportaciones mexicanas de productos petroleros. Dicho aumento fue diferenciado, por temporadas y por artículos, siendo los más favorecidos la kerosena, en un primer momento, y el petróleo crudo, aun cuando el peso relativo de éste decayó con los años. Si bien el detonante de la concentración de las exportaciones que favoreció a Estados

${ }_{55}$ BM, Minerals Yearbook 1942, p. 1123, y BM, Minerals Yearbook 1949, p. 984. ${ }^{56}$ Esto se refleja en la evolución de la inversión petrolera de Estados Unidos en México y Venezuela: de 1943 a 1950 su monto en el primer país pasó de 5 a 13 millones de dólares, en tanto que su valor en la segunda nación pasó de 341 a 857 millones de dólares en los mismos años; es evidente que la expropiación de 1938 y los candados impuestos por México a la inversión extranjera en materia petrolera explican esta tendencia. NACiOnes Unidas, Las inversiones, p. 161; SCHURr, Energy, p. 112 y Yergin, La historia del petróleo, pp. 519 y ss. 
Unidos en la década de 1940 fue el estallido de la guerra en Europa, la menor presencia relativa de Estados Unidos en el comercio de algunos bienes no incluidos en el Tratado sugiere que éste también coadyuvó a apuntalar la concentración antes señalada.

LAS IMPORTACIONES PETROLERAS MEXICANAS PROVENIENTES DE ESTADOS UNIDOS (1943-1950)

Productos importados y nivel de importación

De acuerdo con las SEN/SE, entre 1943 y 1950 las importaciones mexicanas de productos petroleros estadounidenses estuvieron compuestas por petróleo combustible, aceites y grasas lubricantes, gas natural, gasolina cruda o refinada, parafina, kerosena, petróleo crudo, gas oil, vaselina y asfalto. El вм registra también la importación de gases petroleros licuados en ese mismo periodo. ${ }^{57}$ En este ámbito, además, hay que tomar en cuenta que parte de la entrada de derivados de petróleo estadounidenses no quedó registrada en el rubro a causa de la ya mencionada diferencia en el vocabulario arancelario entre México y Estados Unidos. Al respecto, una publicación mexicana comentaba que el aceite para motores y el tetraetilo de plomo llegaban a México bajo la denominación genérica de la fracción 6.63.71 "Mezcla, preparaciones y productos de origen orgánico, mineral y órgano-metálico, no especificados, cuando se compruebe su uso industrial" ${ }^{58}$ Por tanto, las estadísticas con las que contamos subvaluaron esta importación petrolera.

${ }^{57}$ Las SEN/SE registran gases butano y propano, pero desde 1956. Véanse SEN/SE, Anuario Estadístico del Comercio 1939, 1940, 1941, 1943-1944, 19451946, 1947, 1948, 1949-1950, 1956 y BM, Minerals Yearbook 1947, p. 850 y BM, Minerals Yearbook 1950, p. 852.

${ }^{58}$ Fouque, El Tratado, pp. xx-xxi. 
Al margen de ello, los únicos tres productos de esta canasta de importación que fueron incluidos en las fracciones de la Lista I del Tratado de 1942 fueron: el gas natural ${ }^{59} \mathrm{O}$ artificial y las grasas lubricantes, ambos del rubro de bienes de inversión, así como cera mineral y parafinas, del rubro de materias industriales. Esto significa que menos de la tercera parte de los bienes consignados en las estadísticas mexicanas y tres de los doce bienes registrados por las estadounidenses obtuvieron concesiones. En términos de valor, el monto de las importaciones comerciadas en el marco del acuerdo fue de entre 20.6 y $31.2 \%$ del petróleo importado por México de Estados Unidos. Lo anterior sugiere que Estados Unidos tenía otros mercados a los cuales canalizar su petróleo, al tiempo que muestra que dicho país logró introducir su agenda en el acuerdo, pues al final las grasas lubricantes y la cera sí se integraron a la lista.

Ninguno de los tres artículos destacó entre las principales importaciones del Tratado. Sin embargo, como se aprecia en la gráfica 4, su adquisición por parte de México fue, en general, ascendente a lo largo del periodo, aunque con ciertas diferencias: mientras que el incremento de las compras de gas y, en menor escala, de cera fue constante, en el caso de las grasas lubricantes el aumento del valor de los intercambios fue menor; casi se estancó entre 1946 y 1948, y en 1949 experimentó un pronunciado declive-coincidente, de nuevo, con las devaluaciones del peso-, seguido de una acelerada recuperación.

El análisis del índice de concentración de las importaciones mexicanas de productos petroleros (gráfica 5 y cuadro 5) nos muestra que, no obstante las limitaciones impuestas por la guerra, la dependencia del mercado estadounidense fue un

${ }^{59}$ En general, los yacimientos petrolíferos y de gas natural se encontraban en el mismo lugar geográfico, además de que, a principios del siglo xx, una de las tres fuentes de obtención de la gasolina era, precisamente, el gas natural. MiTZakis, The Oil Encyclopedia, p. 214, y Secretaría de Industria, Comercio y Trabajo, Glosario, pp. 203-204. 
común denominador. Con base en los registros de las SEN/SE/ SIYC y de Bancomext para 1934-1960, un total de 10 productos derivados del petróleo fueron importados de Estados Unidos a México, de los cuales sólo 3 estaban contemplados en la Lista I del Tratado. Estos 10 productos se desglosaban en 50 artículos distintos según el medio de transporte mediante el cual se realizaba la importación, los envases que los contenían, o algunas diferencias químicas entre ellos. El índice general de concentración de las importaciones mexicanas de bienes petroleros muestra un alza en el comercio con Estados Unidos a partir de 1934 y, con altibajos, hasta 1940; desde este último año hasta 1955, pese a pequeñas fluctuaciones, el índice de concentración se mantuvo en el orden de más de 95. Posteriormente sí se observan caídas mayores en dicho índice. Por tanto, en términos generales se observa una gran dependencia de la oferta estadounidense por parte de México.

En contraste con los marcados vaivenes que caracterizaron el intercambio de los bienes de exportación analizados en el apartado "Las exportaciones petroleras mexicanas para Estados Unidos (1943-1950)", la trayectoria de estos tres artículos fue más uniforme. Además, la guerra parece no haber sido un punto de quiebre para el crecimiento de su intercambio, no así el fin del conflicto, que, sin lugar a dudas, favoreció la actividad. Es claro que las posibilidades estadounidenses de abastecer a México crecieron luego de 1945. Finalmente, dada la demanda que habían presentado en años anteriores, llama la atención el declive que tuvieron las importaciones de grasas en 1949, quizá por efecto de la devaluación del peso de 1948 y 1949, así como por su inmediata recuperación. 


\section{Gráfica 4}

IMPORTACIONES MEXICANAS DE PRODUCTOS PETROLEROS ESTADOUNIDENSES INCLUIDOS EN EL TRATADO DE 1942 (1943-1950) (MILES DE DÓLARES CONSTANTES 1940=100)

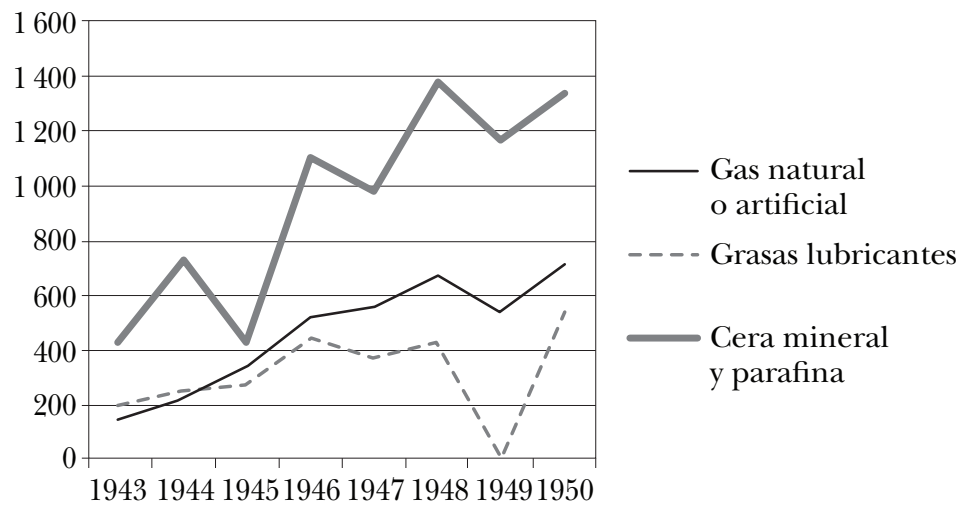

Fuente: BAnCOMEXT, El comercio exterior de México 1940-1948, cuadros 253 y 255; Bancomext, Comercio exterior de México 1950, apéndices 21 y 22.

\section{Gráfica 5}

ÍNDICE DE CONCENTRACIÓN DE LAS IMPORTACIONES MEXICANAS DE PETRÓLEO Y SUS DERIVADOS, 1934-1960

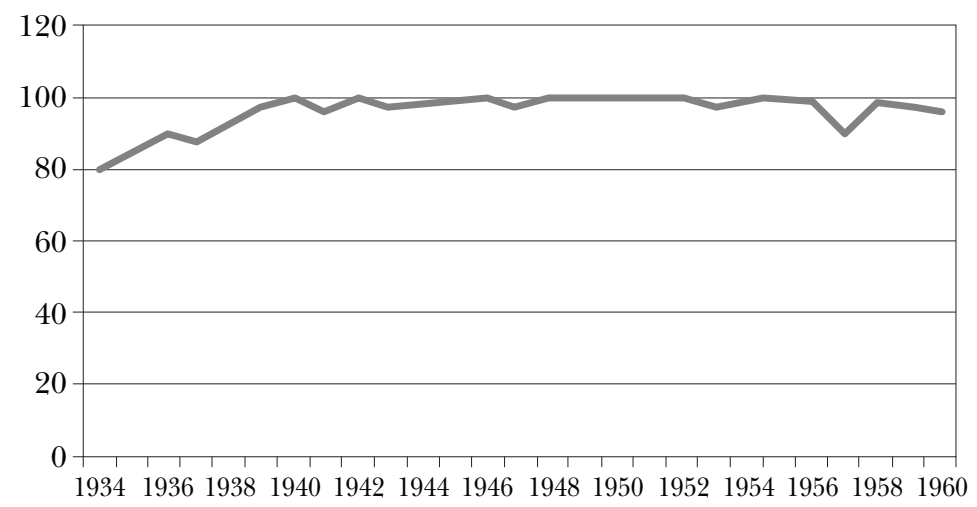

FUENTE: elaboración propia a partir de datos del cuadro A.2 del Anexo. 
Por lo que respecta al índice de concentración de los tres artículos petroleros de importación que sí se incluyeron en el Tratado - grasas lubricantes, gas natural o artificial para alumbrado y ceras y parafinas -, se puede mencionar que, al igual que sucedió con las exportaciones, fue el inicio de la guerra y no el del Tratado el punto de quiebre, el cual reforzó la concentración de las compras de México a favor de Estados Unidos. Si bien Canadá comenzó a exportar algunos de estos bienes a México, lo hizo ya hacia el final del periodo señalado, cuando apenas comenzaba a despuntar como ofertante a nivel internacional. ${ }^{60}$ Durante la vigencia del Tratado estos tres productos tuvieron un índice de concentración constante, con algunas particularidades, lo que sugiere que el acuerdo sí reforzó este comercio bilateral; en el caso de las grasas la mayor concentración se dio de 1946 en adelante. El índice de concentración tuvo más variaciones a lo largo de los años cincuenta. La concentración de la importación de grasas lubricantes presentó ligeras fluctuaciones a la baja en 1944 (a favor de Honduras Británica) y en 1952 (en beneficio de Honduras Británica y Canadá, principalmente). En el gas natural o artificial el punto de menor concentración en los años cuarenta fue 1946 (a favor de Canadá); en el caso específico del gas natural para combustible la concentración de su importación en la oferta de Estados Unidos en más de $96 \%$ muestra que en este producto la colindancia fue un elemento clave para el crecimiento del intercambio porque el transporte del producto se realizaba por tubería. ${ }^{61} \mathrm{Y}$ en las ceras y parafinas, lo mismo que en los lubricantes, 1947 fue el año de menor concentración (en beneficio, mayoritariamente, de Canadá). Vale la pena mencionar que, no obstante estos declives, el índice de concentración de dichas importaciones nunca fue inferior a 90.

60 Véase Hanson, "Natural Gas", p. 188.

${ }^{61}$ Schurr, Energy, p. 132. 


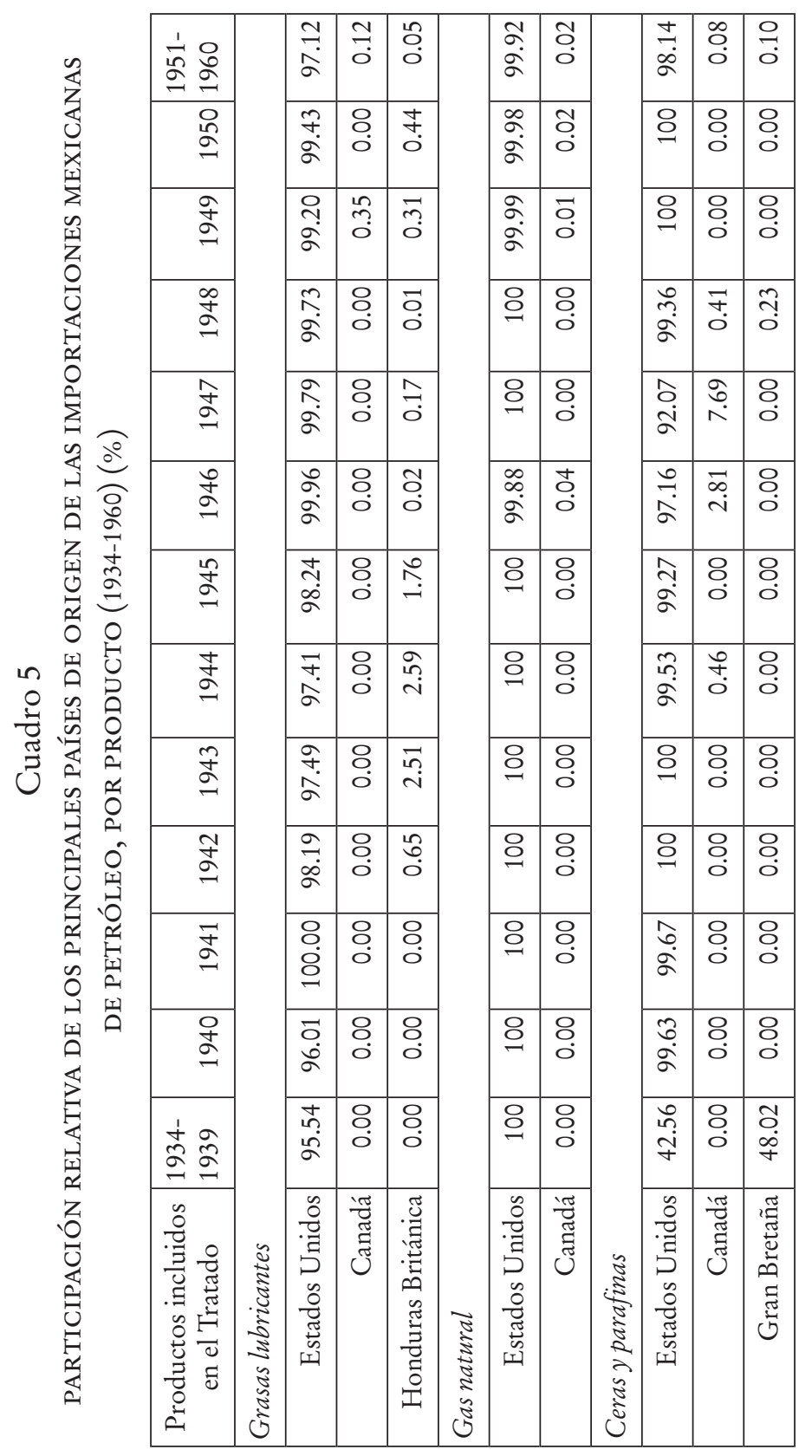




\begin{tabular}{|c|c|c|c|c|c|c|c|c|c|c|c|c|c|c|c|}
\hline & & $\begin{array}{l}\stackrel{n}{\hat{\alpha}} \\
\stackrel{2}{ }\end{array}$ & ণু & & 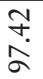 & ठั & & $\begin{array}{l}\tilde{0} \\
\ddot{0}\end{array}$ & O̊. & & ڤ̊ & $\stackrel{\text { ஜ̊ }}{+}$ & & $\begin{array}{l}\text { 華 } \\
\text { হू }\end{array}$ & $\stackrel{\infty}{ণ}$ \\
\hline & & $\begin{array}{l}\stackrel{2}{2} \\
2\end{array}$ & $\stackrel{n}{\circ}$ & & 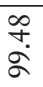 & ปี & & $\begin{array}{l}\stackrel{g}{\alpha} \\
\text { a }\end{array}$ & 웅 & & 으 & 웅 & & $\begin{array}{l}\text { రి } \\
\infty \\
2\end{array}$ & $\stackrel{\varpi}{\sim}$ \\
\hline & & $\begin{array}{l}+ \\
\stackrel{+}{ }\end{array}$ & o̊ & & $\begin{array}{l}\stackrel{N}{2} \\
\stackrel{2}{2}\end{array}$ & $\stackrel{\infty}{\sim}$ & & 으 & 8̊ & & 으 & 8 & & ๙ิ & $\underset{0}{\infty}$ \\
\hline & & $\begin{array}{l}\hat{\sigma} \\
\text { }\end{array}$ & $\begin{array}{l}8 \\
\end{array}$ & & $\begin{array}{l}\text { ๙̃ } \\
\stackrel{\alpha}{ }\end{array}$ & $\begin{array}{l}\infty \\
\text { o } \\
\text { o. }\end{array}$ & & 음 & $\begin{array}{l}\text { O } \\
\text { O̊ }\end{array}$ & & 음 & $\begin{array}{l}8 \\
\end{array}$ & & $\begin{array}{l}\infty \\
\stackrel{\infty}{\alpha} \\
\infty\end{array}$ & ㅇ. \\
\hline & & $\begin{array}{l}\text { 우 } \\
2\end{array}$ & $\stackrel{0}{=}$ & & సิ & 옹 & & 으 & 웅 & & 음 & 웅 & & $\begin{array}{l}\text { กิ } \\
\text { হุ }\end{array}$ & $\stackrel{ \pm}{\rightleftarrows}$ \\
\hline & & $\begin{array}{l}\stackrel{\infty}{\infty} \\
\stackrel{\alpha}{\alpha}\end{array}$ & $\begin{array}{l}\text { oे } \\
\text { o. }\end{array}$ & & $\begin{array}{l}\text { సo } \\
\stackrel{\alpha}{ }\end{array}$ & $\exists$ & & $\begin{array}{r}\hat{\alpha} \\
\dot{\alpha}\end{array}$ & 8 & & 으 & 8 & & $\begin{array}{l}\vec{\infty} \\
\text { ڤं }\end{array}$ & กั? \\
\hline & & $\begin{array}{l}\stackrel{\infty}{\widehat{\alpha}} \\
\stackrel{\alpha}{ }\end{array}$ & $\stackrel{\overbrace{}}{\circ}$ & & ָ̃ & ণ̊ & & $\begin{array}{l}\stackrel{\partial}{\alpha} \\
\text { a }\end{array}$ & 웅 & & 으 & 웅 & & $\begin{array}{l}\text { in } \\
\text { n. } \\
\infty\end{array}$ & $\begin{array}{l}8 \\
\swarrow\end{array}$ \\
\hline & & $\begin{array}{l}\text { f. } \\
\text { gे }\end{array}$ & $\stackrel{n}{\stackrel{n}{f}}$ & & $\vec{m}$ & $\stackrel{N}{\widetilde{O}}$ & & 으 & $\begin{array}{l}\text { Oे } \\
\text { O̊ }\end{array}$ & & 으 & 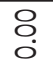 & & $\begin{array}{l}\vec{\sigma} \\
\dot{\infty}\end{array}$ & $\begin{array}{l}n \\
\text { nn } \\
=\end{array}$ \\
\hline & & 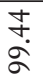 & $\begin{array}{l}\infty \\
+ \\
+\end{array}$ & & $\begin{array}{l}\text { ஸุ } \\
\infty\end{array}$ & $\stackrel{\sigma}{\sigma}$ & & 8 & $\begin{array}{l}8 \\
\end{array}$ & & 8 & $\begin{array}{l}8 \\
\end{array}$ & & $\begin{array}{l}\text { I. } \\
\text { Oु }\end{array}$ & $\begin{array}{l}\stackrel{2}{2} \\
\text { ๙ి }\end{array}$ \\
\hline & & $\begin{array}{l}\text { ஜூ } \\
\text { }\end{array}$ & กี่ & & ণ্ণ & กั & & 으 & Oे & & $\begin{array}{l}\stackrel{a}{\alpha} \\
\stackrel{\alpha}{ }\end{array}$ & 웅 & & $\begin{array}{l}+ \\
\text { ?े } \\
\stackrel{\infty}{ }\end{array}$ & $\begin{array}{l}\stackrel{0}{0} \\
\text { aे }\end{array}$ \\
\hline & & $\hat{\bar{\Omega}}$ & O̊ & & 음 & Oे & & 음 & Oे & & 음 & 웅 & & $\begin{array}{l}\text { 우 } \\
\text { 으 }\end{array}$ & 웅 \\
\hline & & $\overrightarrow{\tilde{a}}$ & Oי & & 음 & O̊ & & ণ্ণ & 웅 & & 으 & 웅 & & $\begin{array}{l}\text { 우 } \\
\text { 으 }\end{array}$ & 웅 \\
\hline & & $\begin{array}{l}\text { 우 } \\
\infty \\
\text { व }\end{array}$ & O̊ & & $\begin{array}{l}\stackrel{\circ}{2} \\
2\end{array}$ & 웅 & & $\underset{ت}{ت}$ & $\underset{m}{+}$ & & $\begin{array}{l}\text { ங் } \\
\text { ங் }\end{array}$ & ஓे & & 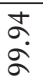 & $\begin{array}{l}\text { Oे } \\
\text { Oे }\end{array}$ \\
\hline 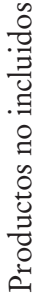 & 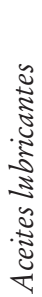 & 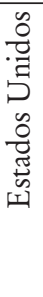 & 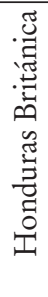 & 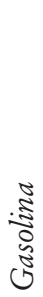 & 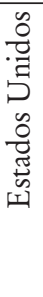 & 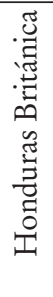 & $\frac{5}{\frac{5}{3}} \frac{\pi}{5}$ & 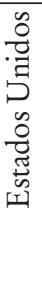 & 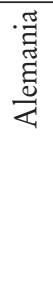 & 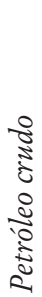 & 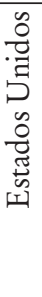 & $\begin{array}{l}\frac{\tilde{J}}{0} \\
\stackrel{N}{N} \\
\stackrel{0}{0} \\
>\end{array}$ & $\begin{array}{l}\vec{\delta} \\
\tilde{\tilde{\sigma}} \\
\tilde{\delta}\end{array}$ & 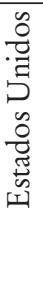 & 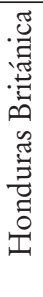 \\
\hline
\end{tabular}


En relación con los artículos que quedaron fuera del Tratado, desde 1935 y hasta 1960 el índice de concentración del petróleo combustible mostró un comportamiento constante con un declive menor en 1943; es prácticamente una línea recta hasta 1960. Una trayectoria similar siguió la concentración de aceites lubricantes, que se elevó desde 1940, y entre 1940 y 1960 se mantuvo a un nivel superior a 99. Por lo que toca a la gasolina, desde 1934 y hasta 1956 tuvo un índice fluctuante a la baja en 1943, 1947, 1954 y 1957 (en beneficio de Honduras Británica). Respecto al asfalto, de 1937 a 1938 su índice de concentración se elevó, manteniéndose así hasta 1957 . Un caso similar fue el de la importación de vaselina, cuya concentración subió de 1939 a 1940 y siguió así hasta 1959. En el petróleo crudo la concentración fue casi una línea recta desde 1935 hasta 1954; luego decreció en 1955 y 1957. Posiblemente debido a esta concentración tan evidente de las compras de México en el mercado estadounidense, ninguno de los productos hasta aquí mencionados se negoció en el acuerdo. Ahora bien, por lo que toca a la kerosena y al gas oil, sus índices de concentración disminuyeron en la primera parte de los años cuarenta: en el primer caso, desde 1942 hasta 1945 incluso, y de nueva cuenta en 1947; y en el segundo, de 1942 hasta 1943 (a favor de Honduras Británica); después comenzó la recuperación, estabilizándose la concentración a favor de Estados Unidos a partir de 1947. Esta trayectoria sugiere que la no inclusión de la kerosena y el gas oil en el Tratado jugó en contra del fortalecimiento de Estados Unidos como único proveedor de dichos productos en el comercio bilateral.

Enseguida discutimos los elementos que explican el comportamiento antes descrito.

\section{Factores determinantes}

En la primera mitad de la década la oferta de productos petroleros estadounidenses fue limitada debido a las necesidades 
impuestas por la guerra y a la falta de nuevos yacimientos petroleros. ${ }^{62}$ Otro elemento que influyó en el monto de las importaciones mexicanas de petróleo estadounidense fue la colindancia de ambos países, sobre todo durante el periodo de la guerra cuando el transporte marítimo se dificultó. ${ }^{63}$ Además del contexto bélico y la ventaja natural que la vecindad geográfica ofrecía, la evidencia disponible indica que el factor determinante de la trayectoria de las importaciones mexicanas de petróleo y sus derivados fueron los requerimientos del mercado interno.

Desde que el Tratado se estaba negociando en 1942, México no sólo era un exportador petrolero, sino también un importador del rubro. Por lo que toca a su adquisición de lubricantes, en noviembre de 1942 el coronel Clarence D. Hicks, representante de varios negocios estadounidenses, le hizo llegar a un agente de Petróleos Mexicanos una propuesta para venderle de 400000 a 600000 galones de bright stock Phillips a lo largo de 1943; es decir, aceites lubricantes derivados de la destilación del petróleo y usados para producir aceites lubricantes para motores. ${ }^{64} \mathrm{La}$ relevancia de la oferta no era menor porque, como mencionaba el propio Hicks en otro documento:

La producción de Petróleos Mexicanos de importantes y vitales aceites lubricantes depende de este Midcontinent Bright Stock y cualquier retraso o suspensión en su embarque, incluso de una semana, es un asunto serio para México. No tienen servicios de almacenamiento para bright stock y deben ordenar con regularidad un carro cada semana $[\ldots]{ }^{65}$

${ }^{62}$ BM, Minerals Yearbook 1940, p. 933, у STоF, Oil, War and American Security, p. 71.

${ }^{63}$ Powell, The Mexican, p. 96, y Banco Nacional de Comercio ExteRIOR, El comercio exterior, p. 9.

${ }^{64}$ AHCOLMEX, FRB, c. 1, exp. 599, s.f. Coronel Clarence D. Hicks a J. M. Velasco, 2 de noviembre de 1942, p. 1 y Lub-Line Lubricants and Additives, http://www.lubline.com/bright-stock/ Consultada el 6/XI/14.

${ }_{65}$ AHCOLMEX, FRB, c. 1, exp. 599, s. f. Coronel Clarence D. Hicks a Ramón Beteta, 25 de marzo de 1942. 
La utilidad del producto ofrecido por Hicks estaba relacionada con las necesidades de las industrias establecidas en México, pero también, en parte, con las restricciones bélicas: "Con maquinaria que no es reemplazada por automóviles y maquinaria nuevos, los viejos tienen que mantenerse en buenas condiciones y esto significa lubricación de alta calidad, para proteger todas las fases de la economía de guerra". ${ }^{66}$

Aunque la propuesta de noviembre de 1942 no se concretó, sabemos que la compañía Phillips había sido proveedora de Petróleos Mexicanos por lo menos durante 1941 y 1942, así que la demanda de lubricantes estadounidenses por parte de la empresa mexicana venía de tiempo atrás. Más aún, para 1946 dicha demanda se mantenía, pues Petróleos Mexicanos continuaba adquiriendo el producto de una pequeña empresa en Oklahoma. ${ }^{67}$ La utilidad que tenían los lubricantes para mantener funcionando maquinaria usada podría sugerir que la demanda mexicana de este tipo de productos debió haber sido mayor durante la segunda guerra mundial que en la posguerra; empero, la trayectoria comercial de las grasas lubricantes no corrobora esta suposición, presuntamente por la imposibilidad estadounidense de satisfacer dicha demanda en medio del conflicto (véase nuevamente la gráfica 4).

En cuanto al gas natural - el segundo producto cuyo intercambio fue importante y se incluyó en el Tratado-, a lo largo del periodo México dependió de su importación. No fue sino hasta el sexenio de Miguel Alemán cuando esta industria comenzó a despuntar en el interior del país. Respecto a la creciente importancia del gas, en 1950 un funcionario mexicano señalaba

${ }^{66}$ AHCOLMEX, FRB, c. 1, exp. 599, s. f. Coronel Clarence D. Hicks a J. M. Velasco, 2 de noviembre de 1942, p. 1.

${ }^{67}$ Parece que la empresa en cuestión era la Midcontinent Petroleum Corporation of Tulsa, a decir de Hicks, el mayor productor de aceites lubricantes en Estados Unidos. AHCOLMEX, FRB, c. 1, exp. 599, s. f. Coronel Clarence D. Hicks a Ramón Beteta, 22 de mayo de 1946. 
que era un combustible "ventajoso", por lo que su uso como calor y fuerza motriz permitiría el establecimiento de otras industrias, como la de fertilizantes. ${ }^{68}$

$\mathrm{Su}$ adquisición también se registra desde los primeros años de operación del Tratado. Por citar algunos ejemplos, una compañía de refinación de zinc en Coahuila se benefició, a partir de junio de 1943, de una tubería - al parecer montada por la propia empresa - para transportar gas natural desde los yacimientos de Texas ${ }^{69}$ Asimismo, mientras estuvo en vigor el régimen de prioridades en Estados Unidos, el War Petroleum Board dio un trato preferente a la importación de gas estadounidense por parte de México. El interés para llevar a cabo dichas importaciones no sólo fue mexicano, pues había compañías estadounidenses que operaban en México y estaban involucradas en esos pedidos - como la Reynosa Pipe Line Company-, y se prolongó más allá de la guerra. Por ejemplo, desde finales de 1942, la American Smelting and Refining Company adquirió varias órdenes para abastecer de gas a México (incluso hasta julio de 1953), y en julio de 1949 asumió el compromiso de elevar los volúmenes exportados previamente. ${ }^{70}$

$\mathrm{Al}$ igual que con las exportaciones, es necesario considerar tanto los artículos incluidos en el Tratado como los que quedaron fuera de él. Los artículos cuya compraventa fue independiente del acuerdo y alcanzó un valor destacado, de miles de dólares constantes, fueron la gasolina y el petróleo combustible, ambos escasos en la República (véase la gráfica 6). ${ }^{71}$

\footnotetext{
${ }_{68}$ Primera Convención, t. I, p. 314.

69 "Mexico. Economic Conditions", Commerce Reports (21 ago. 1943), p. 27. 70 AHSRE, 1437-2, s. f. Vicente Sánchez Gavito a John W. Carrigan, 7 de agosto de 1946 y U.S.A., Federal Power Commission, Notice of application, 31 de marzo de 1950, s. f.

${ }^{71}$ Algunas menciones sobre este problema de escasez se encuentran en "Mexico. Economic Conditions”, Commerce Reports (10 nov. 1945), pp. 33, 35.
} 


\section{Gráfica 6}

VALOR DE LAS IMPORTACIONES DE GASOLINA Y PETRÓLEO

COMBUSTIBLE ESTADOUNIDENSES, 1943-1950

(MILES DE DÓLARES CONSTANTES, 1940=100)

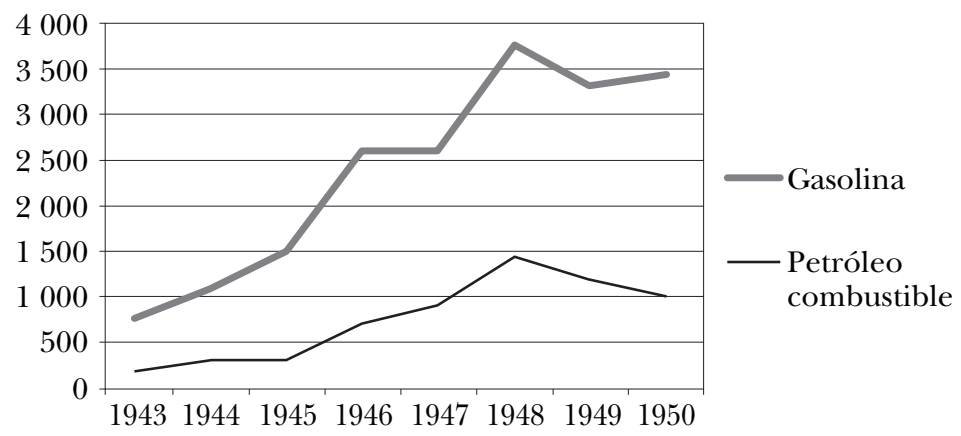

Fuente: SE, Anuario estadístico del comercio 1943-1944, 1945-1946, 1947, 1948, 1949 y 1951.

Descuella, en particular, la creciente presencia de la gasolina, no obstante que el gravamen al que estaba sujeta fue en aumento y que desde octubre de 1948 su importación quedó condicionada a la obtención de un permiso. ${ }^{72}$ Dichas adquisiciones obedecieron tanto a la diferencia entre volumen producido y consumido, como a la distancia que separaba a los centros domésticos de producción de gasolina de los destinos de consumo. Respecto

${ }^{72}$ Los otros productos del rubro que también se sujetaron a permiso fueron el gas oil, el petróleo crudo y la kerosena, SHCP. "Acuerdo que enumera mercancías que quedan sujetas a previo permiso de la Secretaría de Economía, para su importación o exportación”, Diario Oficial de la Federación (30 sep. 1948), pp. 4-5. Para el caso de la gasolina, véanse, por ejemplo, SHCP, “Telegrama circular que fija el impuesto sobre importación de gasolina...”, Diario Oficial de la Federación (15 feb. 1945), p. 2, y Commerce Reports (24 mar. 1945), p. 23, y "Acuerdo que autoriza subsidios a diversas personas y negociaciones para cubrir impuestos de producción, exportación e importación”, Diario Oficial de la Federación (9 mayo 1945), p. 8. 
al primer aspecto, un reporte de 1950 indica que aun cuando el Distrito Federal tenía una refinería en su territorio, no recibía los combustibles que requería. ${ }^{73}$ En relación con el segundo aspecto, desde mayo de 1946 Pemex decidió cubrir los requerimientos del estado de Chihuahua con importaciones de El Paso, Texas, “[...] acortando así considerablemente la distancia que debería recorrerse por ferrocarril y aprovechando las refinerías americanas situadas en aquella frontera, a unos cuantos kilómetros de los puntos de consumo". ${ }^{74}$ Además, se importó gasolina de Los Ángeles con destino a la costa occidental (Sinaloa, Sonora, Nayarit y Jalisco) por la escasez de locomotoras entre Minatitlán y Salina Cruz, y aprovechando el hecho de que los precios en dicha costa eran menores a los prevalecientes en el Golfo. Más adelante, en virtud del resultado favorable de esta estrategia, se optó por comprar combustóleo en Los Ángeles. ${ }^{75}$

En síntesis, es factible afirmar que, en términos generales, las importaciones mexicanas de productos petroleros estadounidenses se elevaron a lo largo de los años cuarenta. Aunque una parte significativa de estas compras se realizó en el marco del Tratado de 1942, el grueso de dicho intercambio en términos de valor y de diversidad de productos tuvo lugar, crecientemente, al margen del acuerdo. En este caso, la fuerte dependencia que tenía México de los productos petroleros estadounidenses se observó en casi todos los bienes comerciales con independencia de su inclusión o exclusión del acuerdo.

\footnotetext{
${ }^{73}$ Primera Convención, t. II, p. 266.

${ }^{74}$ Primera Convención, t. II, p. 267.

${ }^{75}$ La vulnerabilidad de esta estrategia se manifestó cuando en octubre de 1948 se suspendieron las importaciones de petróleo provenientes de California debido a la huelga naviera en la costa oeste de Estados Unidos, "Airgram from the U. S. Embassy at Mexico City (dated October 5, 1948)", Commerce Reports (30 oct. 1948), p. 19.
} 


\section{CONCLUSIONES}

Con base en el análisis realizado en este artículo, es posible concluir que, a pesar de las tensiones diplomáticas y políticas que se dieron entre México y Estados Unidos en la década de 1940 a propósito del oro negro, la compraventa de productos petroleros entre ambas naciones continuó. Dicho flujo fue fluctuante, en varios casos ascendente, y comprendió bienes de inversión y materias industriales diversos en exportaciones e importaciones. En el rubro exportador el intercambio varió, pero sólo en el caso de la kerosena fue mayor durante la segunda guerra mundial, siendo el petróleo crudo el artículo más relevante del periodo. En materia de importación, las transacciones presentaron menos vaivenes, tuvieron un despegue a partir de 1945 y conservaron una trayectoria ascendente, siendo el gas natural el bien con mayor valor de intercambio.

Aunque lo anterior muestra que el Tratado de 1942 sí favoreció el comercio bilateral de petróleo, pues incluyó casi todos los bienes relevantes en este campo, nuestra hipótesis en el sentido de que el Tratado de 1942 impulsó el comercio bilateral de petróleo terminó modificándose. Es cierto que México sacó ventaja al incluir sus bienes petroleros de exportación en el acuerdo, al grado de que la mayor parte de la venta de esta clase de bienes se dio en el marco del Tratado. Sin embargo, no pudo impedir que su importación de grasas lubricantes y cera quedara fuera de la negociación. Más aún, una parte crecientemente importante de los combustibles que México importó no se contemplaron en el acuerdo, por lo que los alcances de éste fueron limitados. Los índices de concentración muestran que el punto de quiebre de los años cuarenta fue el inicio de la segunda guerra mundial, de manera que frente a ella el impulso que el tratado dio al comercio bilateral fue, en la mayoría de los casos, secundario. También evidencian mayor dependencia del mercado estadounidense en la importación que en la exportación. En este sentido, 
cabe subrayar que la industria petrolera mexicana careció de la tecnología doméstica y el capital interno necesarios para seguir desarrollándose, por lo que tuvo que recurrir a Estados Unidos para solventar ambas cuestiones.

Desde esta perspectiva, aunque al inicio del acuerdo hubo incentivos para que ambas partes otorgaran concesiones en materia petrolera, éstos se diluyeron conforme avanzó la década. Las necesidades del mercado interno mexicano en la lógica de la sustitución de importaciones impidieron elevar los volúmenes de exportación, a la vez que Estados Unidos aseguró su presencia en Venezuela y Arabia Saudita y, por ello, una vez concluida la guerra, decreció su interés por controlar el petróleo mexicano. Aun cuando las importaciones mexicanas se elevaron durante el periodo, el acuerdo excluyó concesiones a combustibles, además de que las compañías mexicanas y estadounidenses llegaron a acuerdos propios que aseguraron el suministro de gas natural, independientemente de la suerte del Tratado comercial de 1942. De ahí que la renovación del mismo, en este rubro cuando menos, dejase de ser decisiva tanto para México como para Estados Unidos. 


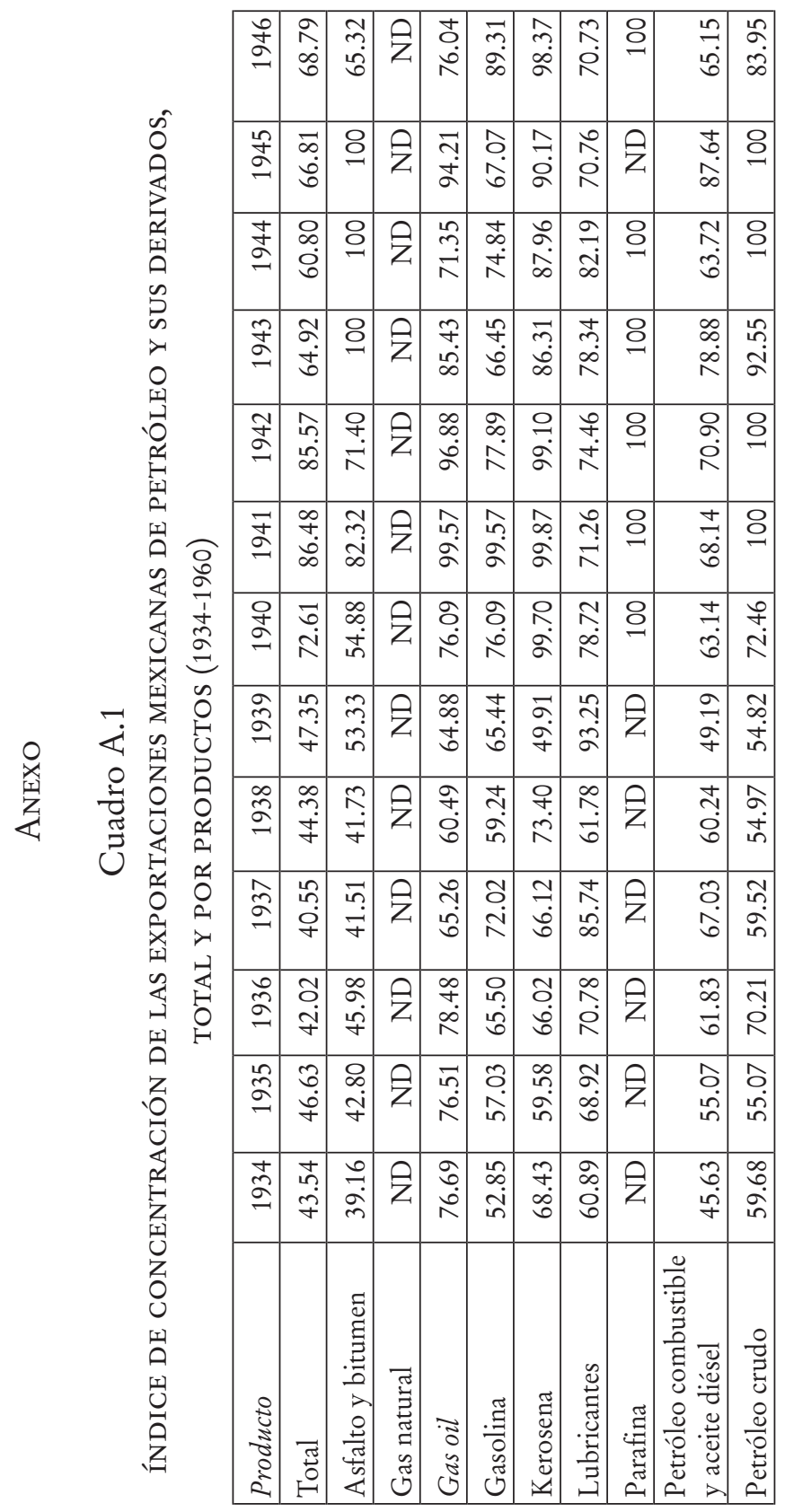




\begin{tabular}{|c|c|c|c|c|c|c|c|c|c|c|c|}
\hline & $\begin{array}{l}\circ \\
\swarrow\end{array}$ & $\begin{array}{l}\vec{q} \\
\dot{q} \\
\dot{q}\end{array}$ & & & $\begin{array}{l}\hat{\alpha} \\
\dot{\alpha}\end{array}$ & \begin{tabular}{l}
0 \\
\multirow{\alpha}{\alpha}{} \\
$\alpha$
\end{tabular} & 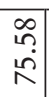 & & $\mathrm{g}$ & $\begin{array}{l}t \\
d \\
\dot{\theta}\end{array}$ & $\begin{array}{l}\infty \\
\hat{1} \\
\dot{2}\end{array}$ \\
\hline & ô & 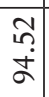 & 으 & 임 & $\begin{array}{l}9 \\
i \\
i\end{array}$ & 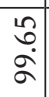 & $\begin{array}{l}\sigma \\
\sigma \\
\sigma\end{array}$ & $\begin{array}{c}a \\
\infty \\
\dot{\sigma} \\
\propto\end{array}$ & 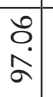 & \begin{tabular}{l} 
In \\
\multirow{2}{*}{}
\end{tabular} & 음 \\
\hline & $\mid \begin{array}{c}0 \\
2 \\
2 \\
=\end{array}$ & 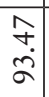 & $\begin{array}{l}\overrightarrow{0} \\
\vec{N}\end{array}$ & $\begin{array}{l}\sigma \\
\sigma \\
\sigma \\
\sigma\end{array}$ & 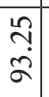 & 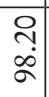 & $\begin{array}{l}\alpha \\
\dot{I}\end{array}$ & $\begin{array}{c}\hat{n} \\
\stackrel{n}{2}\end{array}$ & 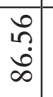 & $\begin{array}{l}\hat{f} \\
\text { }\end{array}$ & 8 \\
\hline & 芯 & $\begin{array}{l}\hat{2} \\
\stackrel{2}{\infty}\end{array}$ & 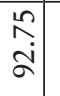 & 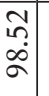 & 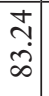 & $\begin{array}{c} \\
\dot{\infty} \\
\dot{\infty}\end{array}$ & 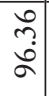 & $\begin{array}{l}\hat{\imath} \\
\stackrel{\infty}{\infty}\end{array}$ & $\begin{array}{c}n \\
\vdots \\
\vdots \\
\alpha\end{array}$ & $\stackrel{m}{\vec{\sigma}}$ & $\begin{array}{c}\hat{\Upsilon} \\
\hat{\infty} \\
\infty\end{array}$ \\
\hline & \begin{tabular}{|l|} 
\\
$\stackrel{2}{=}$ \\
\end{tabular} & 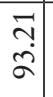 & \begin{tabular}{l|} 
Oे \\
\multicolumn{1}{|c|}{}
\end{tabular} & 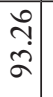 & 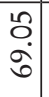 & $\begin{array}{c}\vec{\sigma} \\
\dot{\alpha} \\
\alpha\end{array}$ & 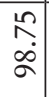 & $\begin{array}{l}+ \\
\stackrel{n}{0} \\
\infty\end{array}$ & 8 & $\begin{array}{l}3 \\
+ \\
\dot{\sigma}\end{array}$ & $\begin{array}{l}\stackrel{2}{\circ} \\
\stackrel{\infty}{\infty}\end{array}$ \\
\hline & 络 & & 之 & & & $\begin{array}{c}\hat{n} \\
\infty \\
\alpha \\
0\end{array}$ & $\begin{array}{l}\infty \\
\infty \\
\dot{\Omega}\end{array}$ & $\begin{array}{l}\hat{n} \\
\text { L }\end{array}$ & $\begin{array}{l}\stackrel{R}{2} \\
\vec{n}\end{array}$ & $\begin{array}{c}0 \\
0 \\
\dot{a} \\
\infty\end{array}$ & $\begin{array}{c}\hat{\sigma} \\
\alpha \\
\alpha\end{array}$ \\
\hline & 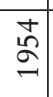 & $\begin{array}{l}1 \\
\dot{\infty} \\
\infty \\
\infty\end{array}$ & 음 & 의 & $\begin{array}{l}\text { ô. } \\
\text { in. }\end{array}$ & $\begin{array}{l}\hat{\partial} \\
\dot{\leftrightarrow}\end{array}$ & $\begin{array}{c}c \\
\text { o. } \\
\dot{\sigma}\end{array}$ & $\begin{array}{l}\hat{\alpha} \\
\dot{\sigma} \\
\dot{\sigma}\end{array}$ & 8 & $\begin{array}{l}a \\
a \\
\dot{\infty} \\
a\end{array}$ & $\frac{\stackrel{\circ}{n}}{\infty}$ \\
\hline & $\stackrel{\hat{\Omega}}{=}$ & $\begin{array}{c}\stackrel{a}{a} \\
\dot{+} \\
\infty\end{array} \mid$ & $\begin{array}{l}\hat{\sigma} \\
\alpha\end{array}$ & $\mathrm{a}$ & 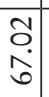 & 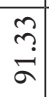 & 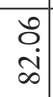 & $\begin{array}{l}\stackrel{+}{1} \\
\dot{\alpha}\end{array}$ & 은 & 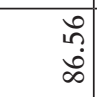 & $\frac{\overrightarrow{2}}{\infty}$ \\
\hline & $\begin{array}{c}1 \\
2 \\
2 \\
2\end{array}$ & 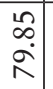 & $\mathrm{z}$ & 으 & $\begin{array}{l}\mathfrak{2} \\
\vdots \\
\vdots\end{array}$ & $\begin{array}{l}\hat{b} \\
\dot{n} \\
\end{array}$ & $\begin{array}{l}\vec{c} \\
i \\
i\end{array}$ & $\begin{array}{l}\hat{N} \\
\hat{\infty}\end{array}$ & 8 & $\begin{array}{l}\infty \\
\infty \\
+ \\
+\end{array}$ & $\begin{array}{l}n \\
\hat{n} \\
\infty\end{array}$ \\
\hline & 茄 & $\begin{array}{l}\stackrel{+}{+} \\
\dot{n} \\
\end{array}$ & 음 & 의 & 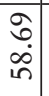 & $\begin{array}{l}\hat{n} \\
\stackrel{n}{n} \\
\infty\end{array}$ & $\begin{array}{l}\tilde{y} \\
\text { for }\end{array}$ & $\begin{array}{l}\stackrel{R}{R} \\
\stackrel{R}{R}\end{array}$ & 8 & 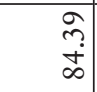 & \begin{tabular}{|c|} 
\\
$\vdots$ \\
0 \\
$\infty$
\end{tabular} \\
\hline & $\begin{array}{l}0 \\
\stackrel{0}{\Omega} \\
\alpha\end{array}$ & 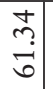 & $\begin{array}{l}\stackrel{n}{\alpha} \\
\alpha \\
\alpha \\
\sigma\end{array}$ & $\mathrm{z}$ & $\begin{array}{l}\hat{o} \\
\text { in. } \\
\text { in }\end{array}$ & $\begin{array}{l}\mathbf{T} \\
\dot{\Phi} \\
\dot{\Phi}\end{array}$ & $\begin{array}{c}0 \\
\text { in } \\
\text { in }\end{array}$ & $\begin{array}{c}R \\
R \\
0, \\
0\end{array}$ & O & $\begin{array}{l}0 \\
0 \\
o \\
0 \\
0\end{array}$ & \begin{tabular}{|l|} 
\\
0 \\
$i$
\end{tabular} \\
\hline & 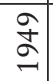 & 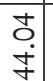 & 으 & 令 & 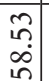 & 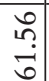 & $\begin{array}{l}0 \\
. \\
0\end{array}$ & 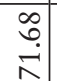 & $\hat{\mathrm{z}}$ & 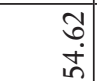 & \begin{tabular}{|c|}
$n$ \\
$\infty$ \\
$\sigma$ \\
$\sigma$
\end{tabular} \\
\hline 政 & 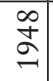 & $\begin{array}{l}\sigma \\
\sigma \\
\dot{q}\end{array}$ & $\begin{array}{l}\stackrel{2}{2} \\
\vdots \\
\alpha\end{array}$ & 合 & 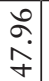 & 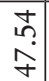 & $\begin{array}{l}\vec{b} \\
\dot{0}\end{array}$ & 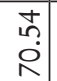 & $\begin{array}{c}\hat{?} \\
\substack{\infty \\
\infty}\end{array}$ & $\begin{array}{l}7 \\
\dot{0} \\
\text { in }\end{array}$ & $\begin{array}{l}\stackrel{\circ}{0} \\
i \\
i n\end{array}$ \\
\hline & \begin{tabular}{l} 
fे \\
\multirow{2}{*}{}
\end{tabular} & $\stackrel{ \pm}{\stackrel{ \pm}{\wedge}}$ & 음 & $\mathrm{z}$ & $\begin{array}{c}\infty \\
\stackrel{\infty}{+} \\
\dot{\infty}\end{array}$ & $\begin{array}{l}\hat{N} \\
\stackrel{0}{0}\end{array}$ & $\begin{array}{l}+ \\
\stackrel{+}{\circ} \\
\alpha\end{array}$ & 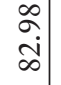 & $\mathrm{z}$ & $\begin{array}{l}\tilde{f} \\
\tilde{n} \\
\hat{n}\end{array}$ & \begin{tabular}{|c|} 
\\
$\stackrel{\dot{\phi}}{\infty}$ \\
\end{tabular} \\
\hline $\overrightarrow{\mathrm{A}}$ & & & $\frac{\sqrt{5}}{\sqrt[n]{4}}$ & & & $\begin{array}{l}:= \\
0 \\
0 \\
\tilde{c} \\
0\end{array}$ & 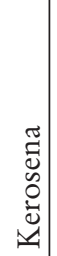 & 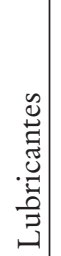 & 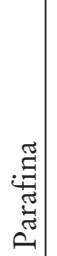 & 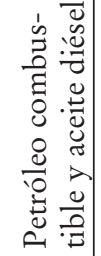 & 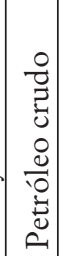 \\
\hline
\end{tabular}




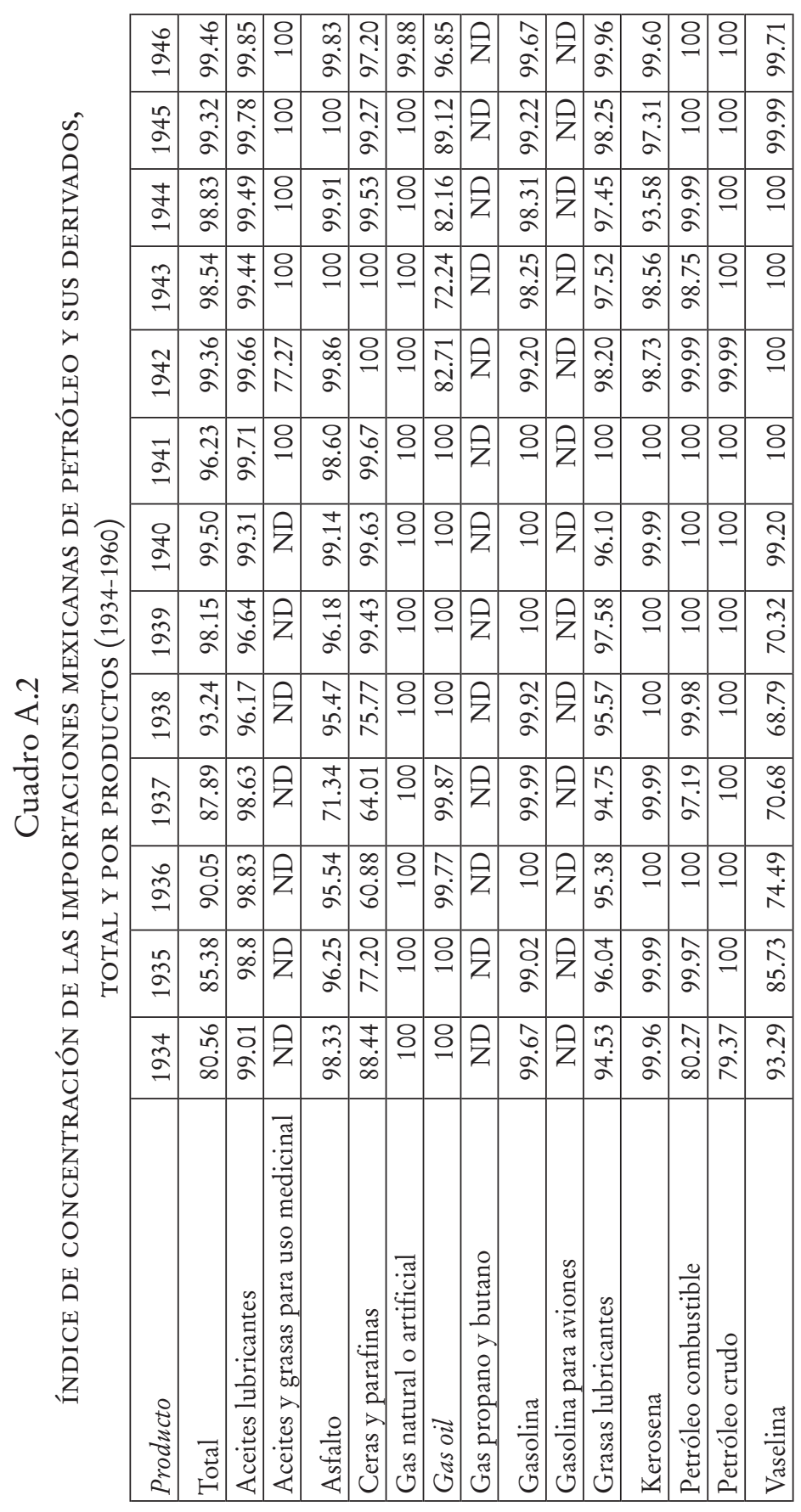




\begin{tabular}{|c|c|c|c|c|c|c|c|c|c|c|c|c|c|c|c|c|c|c|}
\hline \multirow{4}{*}{ 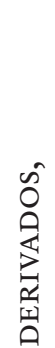 } & \multirow{5}{*}{ 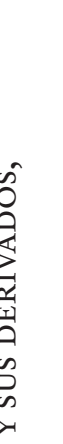 } & 응 & 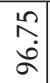 & $\begin{array}{l}\infty \\
\infty \\
2 \\
2\end{array}$ & Z & $\begin{array}{l}\stackrel{\alpha}{ } \\
\stackrel{\alpha}{ }\end{array}$ & $\begin{array}{l}\mathcal{O} \\
\\
\end{array}$ & 음 & 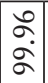 & 으 & $\begin{array}{l}\bar{n} \\
\bar{\sigma}\end{array}$ & 음 & 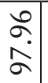 & 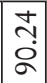 & 豆 & 豆 & 음 & \multirow{2}{*}{ 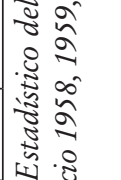 } \\
\hline & & $\stackrel{\approx}{\approx}$ & 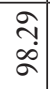 & $\begin{array}{l}\bar{\sigma} \\
\alpha\end{array}$ & 之 & $\stackrel{2}{2}$ & $\begin{array}{l}F \\
\dot{\gamma} \\
\infty\end{array}$ & 으 & 음 & $\begin{array}{l}2 \\
2 \\
\sigma\end{array}$ & 음 & $\begin{array}{l}\Omega \\
\hat{\alpha} \\
\infty\end{array}$ & $\begin{array}{l}+ \\
+ \\
\stackrel{0}{\sigma}\end{array}$ & 음 & $\begin{array}{l}\dot{\sigma} \\
\dot{\sigma}\end{array}$ & 음 & $\begin{array}{l}\stackrel{2}{\sigma} \\
\dot{\sigma}\end{array}$ & \\
\hline & & $\begin{array}{l}\infty \\
\stackrel{2}{\sim}\end{array}$ & $\begin{array}{l}\text { ర్ } \\
\infty \\
\infty\end{array}$ & $\begin{array}{l}\infty \\
\check{a} \\
2\end{array}$ & Z & $\begin{array}{l}\infty \\
\infty \\
\infty\end{array}$ & $\begin{array}{l}\tilde{m} \\
\infty \\
\infty\end{array}$ & 음 & 음 & $\hat{\sigma}$ & $\begin{array}{l}\tilde{\xi} \\
\dot{\ddagger} \\
\check{\sigma}\end{array}$ & 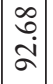 & 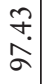 & 음 & 음 & 음 & $\stackrel{2}{2}$ & है \\
\hline & & ڤૂ & $\begin{array}{l}+ \\
\infty \\
\dot{\infty}\end{array}$ & $\begin{array}{l}\tilde{\alpha} \\
\tilde{a}\end{array}$ & Z & $\begin{array}{l}\tilde{6} \\
\stackrel{0}{0}\end{array}$ & $\begin{array}{l}\hat{\gamma} \\
\infty \\
\infty\end{array}$ & $\begin{array}{l}\mp \\
\dot{\sigma} \\
\dot{\sigma}\end{array}$ & \begin{tabular}{|l|}
$\stackrel{m}{a}$ \\
$\stackrel{\alpha}{\alpha}$
\end{tabular} & 으 & \begin{tabular}{l|} 
\pm \\
\multirow{\sim}{\pm}{} \\
\end{tabular} & 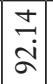 & $\begin{array}{l}\stackrel{7}{+} \\
\stackrel{0}{\sigma}\end{array}$ & $\begin{array}{l}\overrightarrow{0} \\
\text { 。ँ }\end{array}$ & 윽 & 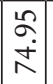 & 음 & |્રી \\
\hline$D_{\infty}^{\infty}$ & & $\stackrel{\circ}{2}$ & $\begin{array}{l}\bar{\sigma} \\
\infty\end{array}$ & $\begin{array}{l}\Omega \\
\hat{\alpha} \\
\end{array}$ & 之 & \begin{tabular}{l}
$\mathfrak{n}$ \\
\multirow{2}{*}{} \\
$\infty$
\end{tabular} & $\begin{array}{l}a \\
\tilde{a} \\
\infty\end{array}$ & $\begin{array}{l}\circ \\
2 \\
2\end{array}$ & \begin{tabular}{|c|} 
\\
$\infty$ \\
$\infty$ \\
$\sigma$ \\
\end{tabular} & 으 & 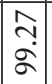 & \begin{tabular}{|l|}
$n$ \\
$\dot{1}$ \\
$\infty$
\end{tabular} & $\begin{array}{l}\text { ڤे. } \\
\text { g. }\end{array}$ & 윽 & 윽 & 음 & $\begin{array}{l}\infty \\
\check{\alpha} \\
2\end{array}$ & \\
\hline 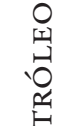 & & 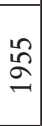 & $\begin{array}{l}\infty \\
\tilde{a} \\
2\end{array}$ & $\hat{\tilde{a}}$ & Z & テี & $\begin{array}{l}n \\
2 \\
\sigma\end{array}$ & $\begin{array}{l}n \\
\hat{\sigma} \\
\sigma\end{array}$ & 응 & 之 & \begin{tabular}{|c|}
$\infty$ \\
0 \\
$\infty$ \\
$\infty$
\end{tabular} & 至 & \begin{tabular}{|l|}
$\circ$ \\
$\dot{\alpha}$ \\
\end{tabular} & 음 & 음 & \begin{tabular}{l|} 
\\
$\infty$ \\
$\dot{0}$ \\
\end{tabular} & 으 & $\frac{a}{2}$ \\
\hline $\begin{array}{l}\sqrt[1]{2} \\
a \\
\text { 됨 }\end{array}$ & О & 䒘 & 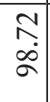 & $\begin{array}{l}\sigma \\
\dot{\sigma}\end{array}$ & Z & $\begin{array}{l}\forall \\
\stackrel{0}{ }\end{array}$ & $\begin{array}{l}\tilde{n} \\
\tilde{\sigma}\end{array}$ & $\begin{array}{l}\infty \\
\dot{\sigma} \\
2\end{array}$ & $\begin{array}{l}\curvearrowright \\
\check{\alpha}\end{array}$ & 至 & 方 & Z & 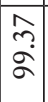 & 음 & 8 & 8 & $\begin{array}{l}\infty \\
\check{a}\end{array}$ & $\hat{\curvearrowright}$ \\
\hline 岕 & $\frac{2}{\frac{1}{1}} \frac{1}{2}$ & $\stackrel{\tilde{\Omega}}{\approx}$ & $\begin{array}{l}\stackrel{ }{\alpha} \\
\hat{\alpha}\end{array}$ & $\begin{array}{l}\Omega \\
\alpha\end{array}$ & 至 & $\begin{array}{l}\curvearrowright \\
\sigma\end{array}$ & $\begin{array}{l}\sigma \\
\hat{\sigma}\end{array}$ & $\begin{array}{l}\dot{a} \\
\dot{\alpha}\end{array}$ & $\begin{array}{l}\bar{\lambda} \\
2 \\
\sigma\end{array}$ & 至 & $\begin{array}{l}\infty \\
\check{\sigma} \\
\sigma\end{array}$ & 至 & 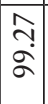 & 윽 & 8 & \begin{tabular}{l|}
$\infty$ \\
$\infty$ \\
$\infty$ \\
$\infty$
\end{tabular} & 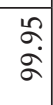 & $\begin{array}{l}0 \\
0 \\
\vdots \\
\vdots \\
5\end{array}$ \\
\hline$\sum_{\substack{x\\
}}^{\vec{x}}$ & $\stackrel{\Xi}{=}$ & ฟี & 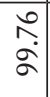 & $\begin{array}{l}+ \\
\tilde{2} \\
2\end{array}$ & Z & ஓे & 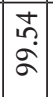 & 음 & 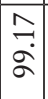 & 至 & $\begin{array}{l}\Xi \\
\sigma \\
\sigma\end{array}$ & $\hat{\mathrm{Z}}$ & $\begin{array}{l}\hat{\sigma} \\
\dot{+} \\
\infty\end{array}$ & 윽 & 음 & $\hat{\mathrm{Z}}$ & $\begin{array}{l}\hat{\infty} \\
\stackrel{\alpha}{ }\end{array}$ & $\frac{0}{\tilde{v}}$ \\
\hline 甹 & مُ & 芯 & $\begin{array}{l}\text { 市. } \\
\text { よे }\end{array}$ & 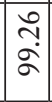 & 至 & $\begin{array}{l}\tilde{\sigma} \\
\stackrel{2}{ }\end{array}$ & $\begin{array}{l}+ \\
\dot{\sigma} \\
\dot{\sigma}\end{array}$ & $\begin{array}{l}\bar{\alpha} \\
\dot{\sigma}\end{array}$ & 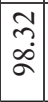 & 至 & $\begin{array}{l}\sigma \\
\dot{\sigma} \\
\dot{\sigma}\end{array}$ & $\hat{\mathrm{Z}}$ & \begin{tabular}{|l|}
$n$ \\
$\stackrel{2}{\alpha}$ \\
\end{tabular} & 음 & 음 & 음 & $\begin{array}{l}\hat{\Omega} \\
\hat{\sigma}\end{array}$ & $\frac{7}{\frac{7}{3}}$ \\
\hline $\begin{array}{l}\sum_{4} \\
\qquad \\
0 \\
0 \\
0\end{array}$ & $\begin{array}{l}5 \\
\alpha \\
0 \\
0\end{array}$ & 융 & $\begin{array}{l}N \\
\stackrel{N}{\alpha}\end{array}$ & $\begin{array}{l}\Omega \\
\hat{\alpha} \\
\end{array}$ & $\begin{array}{c}\text { フุ. } \\
\infty \\
\infty\end{array}$ & 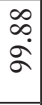 & 음 & \begin{tabular}{|l|}
$\infty$ \\
$\alpha$ \\
$\alpha$
\end{tabular} & \begin{tabular}{|c|}
$\hat{0}$ \\
$\infty$ \\
$\sigma$
\end{tabular} & 豆 & \begin{tabular}{|l|}
$\infty$ \\
+ \\
$\dot{\sigma}$ \\
a
\end{tabular} & Z & \begin{tabular}{|l|}
$\stackrel{m}{a}$ \\
$\stackrel{\alpha}{\alpha}$
\end{tabular} & $\begin{array}{l}\sigma \\
\check{\sigma}\end{array}$ & \begin{tabular}{l|}
$\hat{\infty}$ \\
$\dot{\alpha}$ \\
$\sigma$
\end{tabular} & 으 & 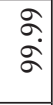 & $\begin{array}{c}101 \\
0 \\
0 \\
3 \\
2\end{array}$ \\
\hline $\begin{array}{l}\sum_{i} \\
\sum \\
\ll\end{array}$ & 胥 & $\stackrel{\sigma}{\sigma}$ & $\begin{array}{l}\approx \\
\dot{\alpha}\end{array}$ & \begin{tabular}{|l|} 
\\
$\infty$ \\
হ \\
\end{tabular} & 윽 & $\begin{array}{l}2 \\
2\end{array}$ & 8 & $\begin{array}{l}\dot{\alpha} \\
\dot{\alpha}\end{array}$ & 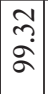 & 豆 & $\begin{array}{l}N \\
\alpha \\
\sigma\end{array}$ & 之 & \begin{tabular}{|l|} 
\\
\multirow{2}{*}{} \\
হ
\end{tabular} & 8 & 8 & 8 & 8 & $\begin{array}{l}\tilde{Z} \\
z \\
z \\
z\end{array}$ \\
\hline 됨 & $H$ & $\stackrel{\infty}{ \pm}$ & $\begin{array}{l}n \\
2 \\
2\end{array}$ & $\begin{array}{l}\hat{\alpha} \\
\alpha\end{array}$ & 으 & $\underset{\sigma}{\sigma}$ & $\begin{array}{l}0 \\
\tilde{2} \\
2\end{array}$ & 8 & \begin{tabular}{|c|}
$\infty$ \\
$\infty$ \\
$\infty$ \\
\end{tabular} & 至 & $\begin{array}{l}\alpha \\
\infty \\
\sigma \\
\sigma\end{array}$ & 台 & 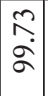 & 음 & \begin{tabular}{l|} 
\\
$\infty$ \\
2 \\
2
\end{tabular} & 음 & 음 & $\begin{array}{l}0 \\
0 \\
0\end{array}$ \\
\hline 岁 & & $\stackrel{\Xi}{\Xi}$ & $\begin{array}{l}+ \\
\stackrel{+}{2} \\
\infty\end{array}$ & $\mid \begin{array}{l}0 \\
2\end{array}$ & 으 & 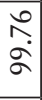 & $\begin{array}{l}\tilde{2} \\
\tilde{\sigma} \\
\end{array}$ & 음 & 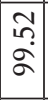 & 至 & \begin{tabular}{|c|}
$\infty$ \\
$\sim$ \\
$\infty$ \\
$\infty$
\end{tabular} & 之 & 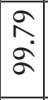 & $\begin{array}{l}\hat{\sigma} \\
\text { à } \\
\end{array}$ & $\begin{array}{l}2 \\
2 \\
\sigma\end{array}$ & 음 & 음 & $\begin{array}{l}0 \\
0 \\
0 \\
0 \\
0\end{array}$ \\
\hline 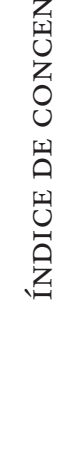 & & 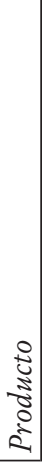 & تี & 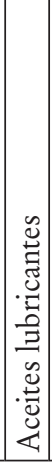 & 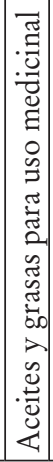 & 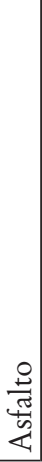 & 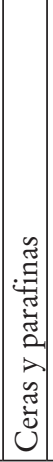 & 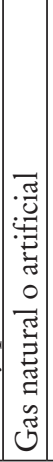 & $\mid$\begin{tabular}{c|}
$\overline{0}$ \\
$\tilde{0}$ \\
$\tilde{u}$ \\
0
\end{tabular} & 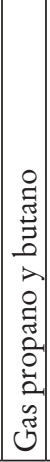 & 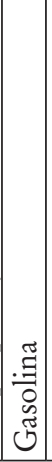 & 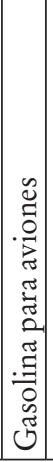 & 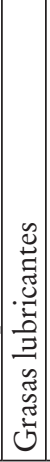 & 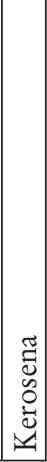 & $\mid \begin{array}{c}0 \\
0 \\
0 \\
0 \\
0 \\
0 \\
0 \\
0 \\
0 \\
0 \\
0 \\
0 \\
\frac{0}{0} \\
0 \\
0 \\
0 \\
0\end{array}$ & 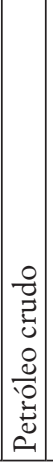 & 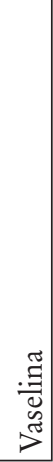 & 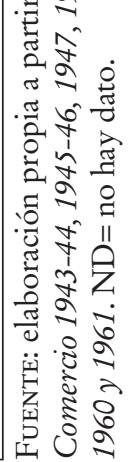 \\
\hline
\end{tabular}




\section{SIGLAS Y REFERENCIAS}

AHCOLMEX, FRB Archivo Histórico de El Colegio de México, fondo Ramón Beteta, Ciudad de México.

AHSRE Archivo Histórico "Genaro Estrada”. Acervo Histórico Diplomático. Secretaría de Relaciones Exteriores de México, fondo Archivo Diplomático, Ciudad de México.

Bancomext Banco Nacional de Comercio Exterior

BM Bureau of Mines

TC Tariff Commission

SE Secretaría de Economía

SEN Secretaría de la Economía Nacional

SIyC Secretaría de Industria y Comercio

SHCP Secretaría de Hacienda y Crédito Público

Avella Alaminos, Isabel, "El comercio de compensación germano-mexicano (1933-1942)", en Iberoamericana. América Latina-España-Portugal, nueva época, II: 7 (2002), pp. 73-90.

Avella Alaminos, Isabel, "Los grupos de intereses en la economía mexicana frente al tratado comercial de 1942 entre México y Estados Unidos (19421950)", en Celaya (coord.), 2014, pp. 475-501.

Avella Alaminos, Isabel, "El impacto del tratado comercial de 1942 entre México y Estados Unidos en el flujo comercial bilateral (1943-1950)", en LOPES y ZuleTA (coords.), 2016, pp. 193-226.

Banco Nacional de Comercio Exterior (Bancomext), El comercio exterior de México 1940-1948, México, Cultura, 1949.

Banco Nacional de Comercio Exterior (Bancomext), Comercio exterior de México 1950, México, Cultura, 1951.

Brown, Jonathan, Oil and Revolution in Mexico, Berkeley, University of California, 1993.

Bureau of Mines, Minerals Yearbook 1940, 1941, 1942, 1947, 1949 y 1950 , Washington, United States Government Printing Office [1941, 1943, 1949, 1951, 1953]. http://digicoll.library.wisc.edu/cgi-bin/EcoNatRes/EcoNatResidx?type=browse\&scope=ECONATRES.MINERALSYEARBK. Consultado el 25 de octubre de 2016. 
CÁrdenas, Enrique, La hacienda pública y la política económica 1929-1958, México, El Colegio de México, Fideicomiso Historia de las Américas, Fondo de Cultura Económica, 2005.

Celaya, Yovana (coord.), Diálogos con una trayectoria intelectual: Marcello Carmagnani, México, El Colegio de México, 2014.

Chacón, Susana, La relación entre México y los Estados Unidos (1940-1955). Entre el conflicto y la cooperación, México, Fondo de Cultura Económica, Tecnológico de Monterrey, 2008.

Chacón, Susana, "La relación petrolera México-Estados Unidos (1946-1952): estudio de caso como fundamento para la integración energética”, en RousSEAU (comp.), 2006, pp. 229-256.

Clash, Thomas W., United States Efforts to Reienter the Mexican Petroleum Industry, 1942-1946, Nueva York, Council on International Studies, State University of New York at Buffalo, Special Studies, núm. 41 [1973].

DeNovo, John A., "The Movement for an Aggresive American Oil Policy Abroad, 1918-1920”, en The American Historical Review, 61: 4 (jul. 1956), pp. 854-876, http://www.jstor.org/stable/1848821.

Confederación de Cámaras Nacionales de Comercio, Tratado de Comercio México-Estados Unidos, México, Publicaciones de la Confederación de Cámaras Nacionales de Comercio, 1943.

"Documentos relacionados con la política petrolera entre México y Estados Unidos 1942-1946” [s.p.i.].

Fouque, Agustín, El Tratado de Comercio México-Americano (guión para una revisión equitativa), México, Edición y Distribución Ibero Americana de Publicaciones, 1949.

Fujigaki Cruz, Esperanza, "Periplo industrial: 1940-1960. Una ojeada al surgimiento de algunas ramas”, en Romero Sotelo (coord.), 1997, pp. 367-415.

Garza Elizondo, Humberto (comp.), Fundamentos y prioridades de la politica exterior de México, México, El Colegio de México, 1986.

Hamilton, Daniel C., Competition in Oil. The Gulft Coast Refinery Market, 1925-1950, Cambridge, Harvard University Press, 1958. 
Hanson, E. J., "Natural Gas in Canadian-American Relations”, en International Journal, 12: 3 (verano 1957), pp. 86-198, http://www.jstor.org/ stable/40198317. Consultado el 6 de octubre de 2016.

Hirschman, Albert O., National Power and the Structure of Foreign Trade, California, University of California Press, 1980.

Kiddle, Amelia y María Cecilia Zuleta (comp.), La expropiación petrolera mexicana en la prensa latinoamericana, México, Archivo Histórico de Petróleos Mexicanos, 2013.

Kuntz Ficker, Sandra, El comercio exterior de México en la era del capitalismo liberal, 1870-1929, México, El Colegio de México, 2007.

Lavín, José Domingo, El problema petrolero, México, Ediciones de la Cámara Nacional de la Industria de Transformación, 1951.

Lopes, Maria Aparecida y María Cecilia Zuleta (coords.), Mercados en común. Estudios sobre conexiones, negocios y diplomacia en las Américas (siglos XIX y XX), México, El Colegio de México, 2016.

Meyer, Lorenzo, México y los Estados Unidos en el conflicto petrolero (19171942), México, El Colegio de México, 1972.

Mitzakis, Marcel, The Oil Encyclopedia, Nueva York Londres, John Siley \& Sons, Chapman \& Hall, 1922.

Naciones Unidas, Las inversiones extranjeras en América Latina, Nueva York, Naciones Unidas, junio de 1955.

Pellicer, Olga, "El petróleo en la política de Estados Unidos hacia México, 1976-1980”, en Foro Internacional, 21: 3 (83) (ene. 1981), pp. 318-335.

Powell, Jack Richard, The Mexican Petroleum Industry: 1938-1950, Berkeley, University of California, 1956.

Primera Convención Técnica Petrolera Mexicana, México, Petróleos Mexicanos, 1950, 2 volúmenes.

Romero Sotelo, María Eugenia (coord.), La industria mexicana y su historia. Siglos XVIII, XIX y XX, México, Universidad Nacional Autónoma de México, 1997. 
Ros, Jaime, et al., El ange petrolero: de la euforia al desencanto, México, Universidad Nacional Autónoma de México, 1987.

Rousseau, Isabelle, América Latina y petróleo: los desafíos políticos y económicos de cara al siglo XXI, México, El Colegio de México, 2010.

Rousseau, Isabelle (comp.), ¿ Hacia una integración de los mercados petroleros en América?, México, El Colegio de México, 2006.

Rubio, María del Mar, "The Role of Mexico in the First World Oil Shortage: 1918-1922, an International Perspective”, en Revista de Historia Económical Journal of Iberian and Latin American Economic History, 24: 1 (primavera 2006), pp. 69-95.

Rubio, María del Mar, C. Yáñez, M. Folchi y A. Carreras, "Energy as an indicator of modernization in Latin America, 1890-1925", en The Economic History Review, New Series, 63: 3 (ago. 2010), pp. 769-804.

Schurr, Sam H. (dir.), Energy in the American economy, 1850-1975, Baltimore, Johns Hopkins University Press, 1960.

Secretaría de Economía-Dirección General de Estadística, Anuario Estadístico del Comercio Exterior de los Estados Unidos Mexicanos 1943-1944, 1945-1946, 1947, 1948, 1949-1950, 1951, 1952, 1953, 1954, 1955, 1956 y 1957, México, Secretaría de Economía [1947, 1947, 1948, 1950, 1951, 1952, 1953 , 1954, 1955, 1956, 1957, 1958].

Secretaría de Economía-Dirección General de Estadística, Anuario estadístico de los Estados Unidos Mexicanos 1939, 1940-1941, 1942, 1943-1945, 1946-1950, México, Secretaría de Economía [1941, 1943, 1948, 1950, 1953].

Secretaría de la Economía Nacional-Dirección General de EstadísTICA, Anuario Estadístico del Comercio Exterior de los Estados Unidos Mexicanos 1939, 1940, 1941 y 1942, México, Secretaría de la Economía Nacional [1941, 1942, 1943, 1946].

Secretaría de la Industria y el Comercio-Dirección General de Estadística, Anuario Estadístico del Comercio Exterior de los Estados Unidos Mexicanos 1958, 1959, 1960 y 1961, México, Secretaría de Industria y Comercio, [1959, 1960, 1961, 1962]. 
Secretaría de Industria, Comercio y Trabajo, Glosario de la industria petrolera y vocabulario español-inglés e inglés-español, México, Talleres Gráficos, 1930.

Senado de la República, Tratados ratificados y convenios ejecutivos celebrados por México, t. VIII (1938-1942), México, Talleres Gráficos de la Nación, 1974.

Silva Herzog, Jesús, Historia de la expropiación de las empresas petroleras, México, Instituto Mexicano de Investigaciones Económicas, 1964.

Stoff, Michael B., Oil, War, and American Security. The search for a national policy on foreign oil, 1941-1947, New Haven, Yale University Press, 1980.

Torres, Blanca, México en la Segunda Guerra Mundial, vol. 19, Historia de la Revolución Mexicana, periodo 1940-1952, México, El Colegio de México, 2005.

Torres, Blanca, Hacia la utopia industrial, vol. 21, Historia de la Revolución Mexicana, periodo 1940-1952, México, El Colegio de México, 2005.

Torres, Blanca (coord.), México y el mundo. Historia de sus relaciones exteriores. De la guerra al mundo bipolar, t. VII, México, El Colegio de México, 2010.

Uhthoff López, Luz María, "La industria del petróleo en México, 19111938: del auge exportador al abastecimiento del mercado interno. Una aproximación a su estudio", en América Latina en la Historia Económica, 33 (ene.-jun. 2010), pp. 5-30.

United States Tariff Commission, Trade agreement between the United States and Mexico. Digests of trade data with respect to products on which concessions were granted by the United States, Washington, United States Tariff Commission, 1943.

Vega, Mercedes de (coord.), Historia de las relaciones internacionales de México, México, Secretaría de Relaciones Exteriores, 2011, vol. 2.

Yergin, Daniel, La historia del petróleo, Buenos Aires, Javier Vergara Editor, 1992. 